\title{
The Use of Physiology-Based Pharmacokinetic and Pharmacodynamic Modeling in the Discovery of the Dual Orexin Receptor Antagonist ACT-541468
}

\author{
Alexander Treiber, Ruben de Kanter, Catherine Roch, John Gatfield, Christoph Boss, \\ Markus von Raumer, Benno Schindelholz, Clemens Muehlan, Joop van Gerven, \\ and Francois Jenck
}

\begin{abstract}
Departments of Preclinical Drug Metabolism and Pharmacokinetics (A.T., R.d.K.), Preclinical Pharmacology (C.R., F.J.), Biology (J.G.), Chemistry (C.B.), Clinical Pharmacology (C.M.), and Preclinical Development (M.v.R., B.S.), Idorsia Pharmaceuticals Ltd, Allschwil, Switzerland; Center for Human Drug Research, Leiden, The Netherlands (J.v.G.)
\end{abstract}

Received March 3, 2017; accepted June 20, 2017

\begin{abstract}
The identification of new sleep drugs poses particular challenges in drug discovery owing to disease-specific requirements such as rapid onset of action, sleep maintenance throughout major parts of the night, and absence of residual next-day effects. Robust tools to estimate drug levels in human brain are therefore key for a successful discovery program. Animal models constitute an appropriate choice for drugs without species differences in receptor pharmacology or pharmacokinetics. Translation to man becomes more challenging when interspecies differences are prominent. This report describes the discovery of the dual orexin receptor 1 and $2\left(\mathrm{OX}_{1}\right.$ and $\left.\mathrm{OX}_{2}\right)$ antagonist ACT- 541468 out of a class of structurally related compounds, by use of physiology-based pharmacokinetic and pharmacodynamic (PBPK-PD) modeling applied early in drug discovery. Although all drug candidates exhibited similar target
\end{abstract}

receptor potencies and efficacy in a rat sleep model, they exhibited large interspecies differences in key factors determining their pharmacokinetic profile. Human PK models were built on the basis of in vitro metabolism and physicochemical data and were then used to predict the time course of $\mathrm{OX}_{2}$ receptor occupancy in brain. An active ACT-541468 dose of $25 \mathrm{mg}$ was estimated on the basis of $\mathrm{OX}_{2}$ receptor occupancy thresholds of about $65 \%$ derived from clinical data for two other orexin antagonists, almorexant and suvorexant. Modeling predictions for ACT541468 in man were largely confirmed in a single-ascending dose trial in healthy subjects. PBPK-PD modeling applied early in drug discovery, therefore, has great potential to assist in the identification of drug molecules when specific pharmacokinetic and pharmacodynamic requirements need to be met.

\section{Introduction}

Insomnia, characterized by difficulties with sleep onset and/or sleep maintenance, affects $10-15 \%$ of the population

All experiments described in this report have been conducted in the research facilities of Actelion Pharmaceuticals Ltd. During manuscript preparation and review, Actelion Pharmaceuticals Ltd was acquired by Johnson \& Johnson, and its drug discovery and early development activities subsequently transferred into a newly created company, Idorsia Pharmaceuticals Ltd. With the exception of Joop van Gerven, all authors of this report were employees of Idorsia Pharmaceuticals Ltd at the time of manuscript publication.

https://doi.org/10.1124/jpet.117.241596.

S This article has supplemental material available at jpet.aspetjournals.org. chronically, with additional $15-20 \%$ suffering from it occasionally. Insomnia has a wide range of effects on quality of life and is associated with increased accident risk and chronic health problems (Zammit, 2007). Historically, insomnia treatments have targeted GABA-A, histamine, serotonin, or melatonin receptors. GABA-A receptor modulators such as zolpidem, which currently dominate the market, tend to increase non-rapid eye movement (non-REM) sleep and decrease REM sleep compared with normal sleep architecture (Bettica et al., $2012 b$ ). This may be the reason for the observed decrease in cognitive performance and locomotor skills when walking during night-time awakening (Otmani et al., 2008; Frey et al., 2011),

ABBREVIATIONS: ACT-541468, (S)-(2-(5-chloro-4-methyl-1H-benzo[d]imidazol-2-yl)-2-methylpyrrolidin-1-yl)(5-methoxy-2-(2H-1,2,3-triazol-2yl)phenyl)methanone; ACT-605143, (S)-(2-(5-chloro-1,4-dimethyl-1H-benzo[d]imidazol-2-yl)-2-methylpyrrolidin-1-yl)(5-methyl-2-(2H-1,2,3-triazol-2yl)phenyl)methanone; ACT-658090, (S)-(2-(6-bromo-4-methyl-1H-benzo[d]imidazol-2-yl)-2-methylpyrrolidin-1-yl)(5-methyl-2-(pyrimidin-2-yl)phenyl)methanone; ADAM, advanced dissolution, absorption, and metabolism; AUC, area under the plasma concentration versus time curve; AUC $_{0-\text { last }}$, area under the plasma concentration versus time curve up to the last measurable concentration; $C L$, total plasma clearance; $\mathrm{CL}_{\text {int }}$, intrinsic clearance; $\mathrm{C}_{\text {max }}$, peak observed plasma concentration; CRC, concentration-response curve; DMSO, dimethyl sulfoxide; DORA, dual orexin receptor antagonist; EEG, electroencephalogram, -graphic; EMG, electromyogram, -graphic; G418, $(2 R, 3 S, 4 R, 5 R, 6 S)-5$-amino-6-[(1R,2S,3S,4R,6S)-4,6-diamino-3-[(2R,3R,4R,5R)-3,5dihydroxy-5-methyl-4-methylaminooxan-2-yl]oxy-2-hydroxycyclohexyl]oxy- 2-(1-hydroxyethyl)oxane-3,4-diol; $\mathrm{K}_{\mathrm{b}}$, inhibition constant as determined by a functional assay; LC-MS/MS, liquid chromatography coupled to mass spectrometry; logD, distribution coefficient; MK-1064, 5-(5-chloro-3-pyridyl)-N-((5,6-

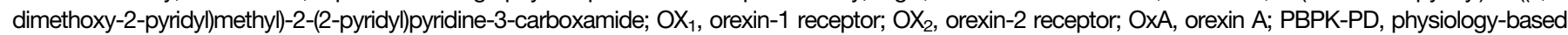
pharmacokinetic and pharmacodynamic (modeling); PD, pharmacodynamic; PK, pharmacokinetic; REM, rapid eye movement; ROt $t_{1 / 2}$, receptor occupancy half-life; SB-649868, N-([(2S)-1-([5-(4-fluorophenyl)-2-methyl-4-thiazolyl]carbonyl)-2-piperidinyl]methyl)-4-benzofurancarboxamide; $\mathrm{T}_{\max }$, time to reach peak plasma concentration; $\mathrm{V}_{\mathrm{ss}}$, apparent volume of distribution at steady-state; $\sigma_{\mathrm{g}}$, geometric standard deviation. 
the latter being of particular concern for the elderly (Glass et al., 2005).

The orexin system was discovered in the late 1990s (de Lecea et al., 1998; Sakurai, 1999) and is composed of two peptides, orexin $\mathrm{A}(\mathrm{OxA})$ and orexin $\mathrm{B}(\mathrm{OxB})$, produced in a small number of neurons in the lateral hypothalamus, and two $\mathrm{G}$ proteincoupled receptors, orexin-1 $\left(\mathrm{OX}_{1}\right)$ and orexin-2 $\left(\mathrm{OX}_{2}\right)$, widely expressed throughout the brain. Orexin deficiency has been linked to human narcolepsy/cataplexy, a neurologic disorder in which patients suffer from an uncontrolled sleep-wake cycle (Peyron et al., 2000; Thannickal et al., 2000). This indicates that the orexin system plays an essential role in promoting alertness and maintaining wakefulness under motivational circumstances. It supports behavioral and physiologic adaptation to relevant internal and external environmental stimuli, such as physiologic need states, exposure to threats, or reward opportunities (Sakurai, 2007; Carter et al., 2009; Tsujino and Sakurai, 2009; Mahler et al., 2014).

With the discovery of potent low-molecular-weight compounds, orexin receptor antagonism has emerged as a novel concept for the treatment of insomnia disorders. Unlike classic hypnotics targeting GABA-A, histamine, or serotonin receptors, orexin receptor antagonists promote sleep in a distinct manner, as they maintain a natural sleep architecture and do not impair cognitive function or locomotor skills (Hoever et al., 2012b; Ramirez et al., 2013; Tannenbaum et al., 2016).

Both, dual orexin receptor antagonists (DORAs) including almorexant (Hoever et al., 2012b), suvorexant (Herring et al., 2012), filorexant (Connor et al., 2016), lemborexant (Yoshida et al., 2015), and SB-649868 (Bettica et al., 2012a), as well as the $\mathrm{OX}_{2}$-selective antagonist seltorexant have been tested in insomnia patients (Bonaventure et al., 2015a). Polysomnography in animals and healthy human subjects suggest a qualitatively comparable sleep-promoting profile for both, DORAs and $\mathrm{OX}_{2}$ selective compounds, although relative impact on REM versus non-REM sleep may differ (Dugovic et al., 2014; Jacobson et al., 2017). Comparative studies with DORAs and $\mathrm{OX}_{2}$-selective compounds indicate that higher $\mathrm{OX}_{2}$ receptor occupancies are required by $\mathrm{OX}_{2}$-selective compounds (Mieda et al., 2011; Gotter et al., 2016), as recently shown with the DORA filorexant and the $\mathrm{OX}_{2}$-selective MK-1064. As $\mathrm{OX}_{1}$-selective antagonists alone lack sleep-promoting efficacy (Gozzi et al., 2011), the overall data suggest a complementary role of $\mathrm{OX}_{1}$ antagonism in the sleeppromoting efficacy of DORAs. $\mathrm{OX}_{1}$ receptors also appear to play an essential role in anxiety states (Merlo Pich and Melotto, 2014), and $\mathrm{OX}_{1}$-selective antagonists additionally attenuate behavioral and cardiovascular responses to stress without altering baseline motor or autonomic functions (Gozzi et al., 2011; Johnson et al., 2012; Bonaventure et al., 2015b).

In 2014, suvorexant was approved in the United States under the trade name Belsomra for the treatment of insomnia. During regulatory review, the Food and Drug Administration expressed concerns about potential next-day residual effects (Citrome, 2014; Vermeeren et al., 2015) associated with higher Belsomra doses as a consequence of its extended plasma halflife. This episode highlights the importance of identifying compounds with an optimal pharmacokinetic and pharmacodynamic (PK/PD) profile in man during the discovery process of an insomnia drug.

From a drug discovery perspective, the identification of candidate molecules for the treatment of insomnia poses particular challenges. Beyond pharmacological target potency and brain penetration as basic requirements, rapid onset and adequate sleep duration are key features. For compounds with little interspecies differences in receptor pharmacology and pharmacokinetics, appropriate drug candidates might be readily identified on the basis of animal pharmacology data. Translational aspects become more important for molecules exhibiting pronounced interspecies differences in drug disposition. For example, plasma protein binding affects drug distribution into tissues and total blood clearance, and thus influences the pharmacokinetic half-life of a drug. Physiologybased pharmacokinetic and pharmacodynamic (PBPK-PD) modeling has been established as an appropriate tool to translate animal PK and PD data into man early in drug development (Jones et al., 2009). The present report describes the central and early role of PBPK-PD modeling in drug discovery as a key tool in the selection process of ACT-541468, a DORA that is currently in phase 2 clinical development for the treatment of insomnia disorders. Although this report focuses on only three prototypical compounds, the approach was in fact applied to a set of about 20 structural analogs from the same chemical class.

\section{Materials and Methods}

Chemicals and Reagents. $(S)-(2-(5$-chloro-4-methyl- $1 \mathrm{H}-$ benzo[d]imidazol-2-yl)-2-methylpyrrolidin-1-yl)(5-methoxy-2-(2H-1,2,3triazol-2-yl)phenyl)methanone (ACT-541468), (S)-(2-(5-chloro-1,4-dimethyl1H-benzo[d]imidazol-2-yl)-2-methylpyrrolidin-1-yl)(5-methyl-2-(2H-1,2,3triazol-2-yl) phenyl)methanone (ACT-605143), (S)-(2-(6-bromo-4-methyl1H-benzo[d]imidazol-2-yl)-2-methylpyrrolidin-1-yl)(5-methyl-2-(pyrimidin2-yl)phenyl)methanone (ACT-658090) (Fig. 1), almorexant, suvorexant, and their corresponding salts were synthesized by the medicinal chemistry department of Actelion Pharmaceuticals Ltd (Allschwil, Switzerland) as described in Supplemental Fig. S1, or according to published methods (Baxter et al., 2011; Mangion et al., 2012; Boss et al., 2013; Verzijl et al., 2013; Boss et al., 2015a,b). Chemical purity of all compounds was in excess of $97 \%$.

Orexin Receptor Antagonist Assays. OxA curve shift experiments were performed to determine the surmountability of antagonism and to calculate the antagonistic potency [apparent inhibition constant as determined by a functional assay $\left(\mathrm{K}_{\mathrm{b}}\right)$ ] of the three benzimidazole compounds. Chinese hamster ovary ( $\mathrm{CHO}$ ) cells expressing the human or rat $\mathrm{OX}_{1}$ or $\mathrm{OX}_{2}$ receptors were grown in culture medium (Ham's F-12 with L-glutamine; Life Technologies/Thermo Fisher Scientific, Waltham, MA) containing $300 \mu \mathrm{g} / \mathrm{ml}$ (for human receptorexpressing cells) or $1000 \mu \mathrm{g} / \mathrm{ml}$ (for rat receptor-expressing cells) G418, $100 \mathrm{IU} / \mathrm{ml}$ penicillin, $100 \mu \mathrm{g} / \mathrm{ml}$ streptomycin, and $10 \%$ heat-inactivated fetal calf serum (FCS). Prior to the experiment, the cells were seeded at 20,000 cells/well into 384-well black clear-bottom sterile plates (Greiner/Sigma-Aldrich, St. Louis, MO) and incubated overnight at $37^{\circ} \mathrm{C}$ in $5 \% \mathrm{CO}_{2}$. On the day of the assay, culture medium in each well was replaced with $50 \mu \mathrm{l}$ of staining buffer [1× Hanks' balanced salt solution (HBSS), $1 \%$ FCS, 20 mM HEPES, $0.375 \mathrm{~g} / \mathrm{l} \mathrm{NaHCO}_{3}, 5 \mathrm{mM}$ of the organic anion transporter (OAT) inhibitor probenecid (Sigma-Aldrich), $3 \mu \mathrm{M}$ of the fluorogenic
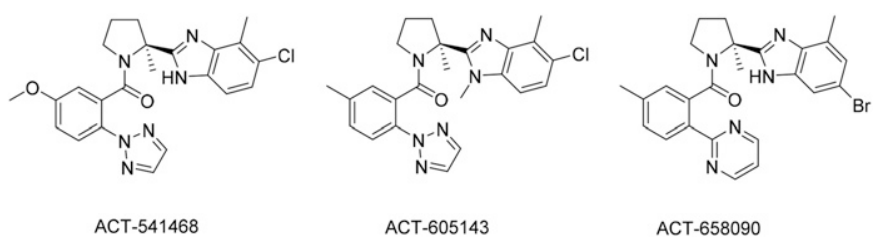

Fig. 1. Chemical structures of ACT-541468, ACT-605143, and ACT658090 . 
TABLE 1

Mean apparent $\mathrm{K}_{\mathrm{b}}$ values for selected dual orexin receptor antagonists in calcium release assays determined in $\mathrm{CHO}$ cells expressing human $\mathrm{OX}_{1}$ and $\mathrm{OX}_{2}$ receptors $(n \geq 3)$

\begin{tabular}{cccccc}
\hline \multirow{2}{*}{ Receptor } & \multicolumn{5}{c}{$\mathrm{K}_{\mathrm{b}}\left[\sigma_{\mathrm{g}}\right](\mathrm{nM})^{a}$} \\
\cline { 2 - 5 } & Suvorexant & Almorexant & ACT-541468 & ACT-605143 & ACT-658090 \\
\hline Human OX & $0.68[2.0]$ & $4.5[2.3]$ & $0.52[2.0]$ & $0.62[1.5]$ & $8.3[1.2]$ \\
Human OX & $0.42[1.9]$ & $0.42[2.2]$ & $0.78[1.5]$ & $0.70[1.6]$ & $5.9[1.4]$ \\
\hline
\end{tabular}

$\sigma_{\mathrm{g}}$, geometric standard deviation.

${ }^{a} \mathrm{~K}_{\mathrm{b}}$ values were derived from $\mathrm{IC}_{50}$ values using the generalized Cheng-Prusoff equation, and their geometric means are shown.

calcium indicator fluo-4 AM (Life Technologies/Thermo Fisher Scientific), and 10\% pluronic F-127 (Life Technologies/Thermo Fisher Scientific) ]. The cell plates were incubated for 1 hour at $37^{\circ} \mathrm{C}$ in $5 \% \quad \mathrm{CO}_{2}$ followed by equilibration at room temperature for $\geq 30$ minutes. Fluo-4-stained cells were supplemented with $10 \mu \mathrm{l}$ of $1: 10$ serially diluted 6 -fold concentrated antagonist solution in the assay buffer $(1 \times$ HBSS buffer, $0.1 \%$ bovine serum albumin, $20 \mathrm{mM}$ HEPES, $0.375 \mathrm{~g} / \mathrm{l} \mathrm{NaHCO}_{3}, \mathrm{pH}$ 7.4) containing $0.6 \%$ dimethyl sulfoxide (DMSO). After 120 minutes, cells were stimulated with $10 \mu \mathrm{l}$ of $1: 5$ serially diluted $7 \times$ OxA solution in assay buffer containing $\leq 0.1 \%$ methanol, resulting in final concentrations between 0.01 and $1000 \mathrm{nM}$. Calcium mobilization (proportional to OX receptor activation by $\mathrm{OxA}$ ) was measured using the fluorescence imaging plate reader (FLIPR) assay (Tetra, excitation: 470-495 nm; emission: 515-575 nm; Molecular Devices, Sunnyvale, CA). To calculate the apparent $K_{b}$ values, FLIPR traces were subjected to spatial uniformity correction and normalized by trace alignment at the last time point before agonist addition (ScreenWorks software; Molecular Devices). The maximum fluorescence signals per well were used to generate OxA concentration-response curves (CRCs) in GraphPad Prism (GraphPad Software, LaJolla, CA). The EC $_{50}$ values and Hill slopes (n) for the OxA CRCs, and the $\mathrm{IC}_{50}$ values of the antagonists at approximately $\mathrm{EC}_{70}$ of $\mathrm{OxA}$ (1.6 nM for human $\mathrm{OX}_{1}$ and $\mathrm{OX}_{2}, 8 \mathrm{nM}$ for rat $\mathrm{OX}_{1}$ and $\mathrm{OX}_{2}$ ) were calculated using the proprietary $\mathrm{IC}_{50}$ Witch software (curve-intrinsic minima and maxima were used). The apparent $K_{b}$ values were calculated via the generalized Cheng-Prusoff equation, using the on-day OxA $\mathrm{EC}_{50}$ value $\left(\mathrm{EC}_{50 \mathrm{OxA}}\right)$ and the OxA concentration used for stimulation $\left(\left[\mathrm{OxA} \mathrm{A}_{\text {stim }}\right]\right.$ ), with the following formula (Cheng and Prusoff, 1973; Miller et al., 1999):

$$
K_{b}=\frac{\mathrm{IC}_{50}}{\left(2+\left(\frac{\left[\mathrm{OxA}_{\mathrm{stim}}\right]}{\mathrm{EC}_{500 \mathrm{xA}}}\right)^{n}\right)^{\frac{1}{n}}-1}
$$

Approximate receptor occupancy half-lives $\left(\mathrm{ROt}_{1 / 2}\right)$ of the antagonists were determined using calcium release assays after antagonist washout. To this end, fluo-4-stained CHO cells were supplemented with $10 \mu \mathrm{l}$ of $6 \times$ concentrated antagonists (serially diluted 1:10 in assay buffer with $0.6 \%$ DMSO). After 120 minutes, cells were washed extensively with assay buffer and then stimulated at several time points (0-63 minutes) with $10 \mu \mathrm{l}$ of a $7 \times \mathrm{OxA}$ solution, giving a final $\mathrm{OxA}$ concentration of $\mathrm{EC}_{70}$. Compound incubations and washout phase were performed at $37^{\circ} \mathrm{C}$. Calcium mobilization was measured, and $\mathrm{IC}_{50}$ values were calculated and converted to the apparent $\mathrm{K}_{\mathrm{b}}$ values via the generalized ChengPrusoff equation, using the OxA CRC slope determined at every time point, as described above (software settings: curve-intrinsic maximum; fixed minimum: full block by $10 \mu \mathrm{M}$ suvorexant). The geometric means of $\mathrm{K}_{\mathrm{b}}$ values generated in three independent experiments were then plotted on a semilogarithmic scale against time. The $\mathrm{ROt}_{1 / 2}$ was calculated from the $\mathrm{K}_{\mathrm{b}}$ values obtained at

\section{Suvorexant}

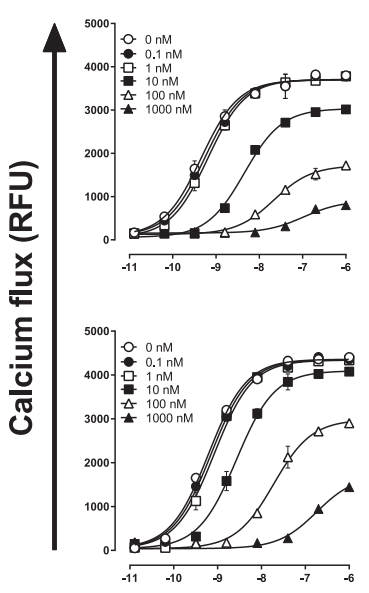

Almorexant
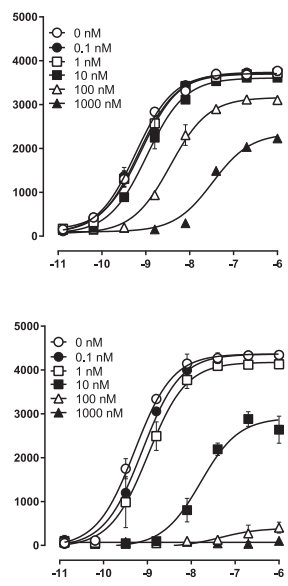

ACT-541468
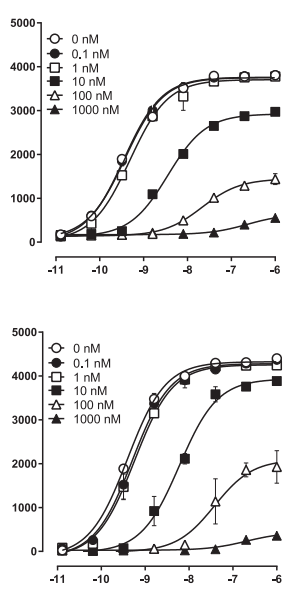

АCT-658090
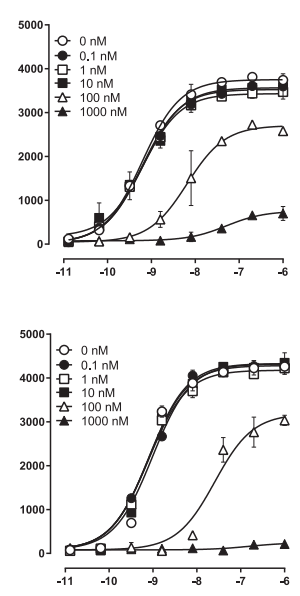

ACT-605143
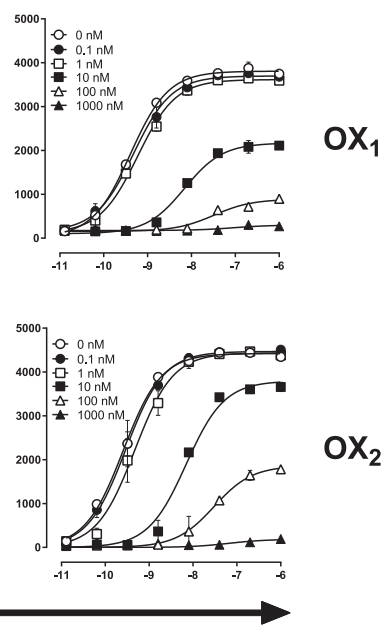

\section{OxA concentration ( $\log M)$}

Fig. 2. Effect of dual orexin receptor antagonists on OxA-induced calcium flux in CHO cells expressing recombinant human $\mathrm{OX}_{1}$ or $\mathrm{OX}_{2}$ receptors. Cells were stained with fluo-4 and preincubated with dilution series of antagonists for 120 minutes followed by the addition of a dilution series of OxA. Peak fluorescence values were converted to CRCs. Data shown are the average of duplicate values ( \pm S.D.) from a representative of at least three experiments. $\mathrm{IC}_{50}$ values at $1.6 \mathrm{nM}$ OxA were determined and used as a basis to calculate the apparent $\mathrm{K}_{\mathrm{b}}$ via the generalized ChengPrusoff equation. 
TABLE 2

Receptor occupancy half-lives of orexin receptor antagonists at human $\mathrm{OX}_{1}$ and $\mathrm{OX}_{2}$ receptors as determined by calcium flux measurements after compound washout

\begin{tabular}{ccccccc}
\hline Receptor & Parameter $^{a}$ & Suvorexant & Almorexant & ACT-541468 & ACT-605143 & ACT-658090 \\
\hline Human $\mathrm{OX}_{1}$ & $\mathrm{~K}_{\mathrm{b} \_0 \text { min }}(\mathrm{nM})$ & 0.87 & 9.3 & 0.83 & 0.14 & 5.5 \\
& $\mathrm{~K}_{\mathrm{b} \_33 \min }(\mathrm{nM})$ & 11 & 26 & 13 & 6.1 & 104 \\
& $\mathrm{ROt}_{1 / 2}(\min )$ & 9 & 22 & 8 & 6 & 8 \\
Human $\mathrm{OX}_{2}$ & $\mathrm{~K}_{\mathrm{b} \_0 \text { min }}(\mathrm{nM})$ & 0.48 & 0.11 & 1.1 & 0.34 & 9 \\
& $\mathrm{~K}_{\mathrm{b} \_33 \min }(\mathrm{nM})$ & 18 & 0.59 & 224 & 68 & 54 \\
& $\mathrm{ROt}_{1 / 2}(\mathrm{~min})$ & 6 & 14 & 4 & 4 & 13 \\
\hline
\end{tabular}

${ }^{a} \mathrm{~K}_{\mathrm{b}}$ values were derived from $\mathrm{IC}_{50}$ values using the generalized Cheng-Prusoff equation, and their geometric mean is shown.

0 and 33 minutes after washout, assuming first-order dissociation kinetics, with the following formula:

$$
\mathrm{ROt}_{1 / 2}=\frac{33 \mathrm{~min}}{\log _{2}\left(\frac{K_{b 33 \min }}{K_{b 0 \min }}\right)}
$$

Animal Housing. Male, adult Wistar rats were used for pharmacokinetic [Crl:WI(Han) (Charles River, Sulzfeld, Germany)] and pharmacology experiments [RccHan:WIST (Harlan, Horst, The Netherlands) or Crl:WI(Han)]. All rats were maintained under standard laboratory conditions [temperature $20 \pm 2^{\circ} \mathrm{C}$, relative humidity 55-70\%, standard Provimi Kliba diet 3336 (Kaiseraugst, Switzerland, www.kliba-nafag.ch), and domestic mains tap water ad libitum] on a regular 12-hour light-dark cycle (lights on 6:00 AM). After arrival, rats were allowed at least one week of acclimatization to Actelion's animal facility and were carefully monitored to ensure good health and suitability for inclusion in the study. Unless noted otherwise, rats were socially housed in groups of four in standard plastic rodent cages, and all tests were conducted during the light phase (8:00 AM to 6:00 PM) under illumination of $>600 \mathrm{~lx}$.

Pharmacokinetic experiments in the Beagle dog were performed in the Shanghai animal facilities of Actelion Pharmaceuticals Ltd in accordance with the Swiss animal protection law. The dogs were group-housed during the study and only separated for feeding and monitoring of clinical signs. With the exception of a period of fasting from the night before dose administration until 4 hours after dose administration, animals were given a daily allowance of $350 \mathrm{~g}$ of a standard laboratory diet and had free access to tap water.

All animals were housed in accordance with the National Institutes of Health guidelines and experimental procedures were approved by the Basel-Landschaft Veterinary Office and strictly adhered to Swiss federal regulations on animal experimentation. Well-being of animals was monitored during the day by trained technical staff. Animals were checked for body weight loss, abnormal breathing, pilo-erection, grooming, and locomotion as criteria of distress according to the company's animal welfare policy and guideline on humane endpoints.

Pharmacokinetic Experiments in Rat and Dog. Male Wistar rats $(n=3)$ with a body weight of ca. $200-250 \mathrm{~g}$ were used for pharmacokinetic experiments under license no. 169. For intravenous sampling, a jugular vein catheter was implanted 2 days prior to drug dosing under aseptic conditions. After recovery from general isoflurane anesthesia, animals were housed individually with free access to water and food during the recovery period and the entire duration of the experiment. Compounds for intravenous use were formulated as aqueous solution in 30\% 2-hydroxypropyl-beta-cyclodextrin (HP $\beta \mathrm{CD}$ ) starting from a 5\% stock solution in DMSO. For oral gavage dosing, compounds were formulated as either a suspension in $0.5 \%$ methyl cellulose or as solution in PEG400.

Male Beagle dogs $(n=3)$ with body weights of $14.3-15.6 \mathrm{~kg}$ at the start of treatment were used in a crossover design with a washout period of 7 days under license number 2016-06-QCB-32. All experiments were performed in fasted state, and gastric $\mathrm{pH}$ was controlled by giving intramuscular pentagastrin at a dose of $6 \mu \mathrm{g} / \mathrm{kg} 20$ minutes before and 30 minutes after oral dosing. For intravenous dosing, compounds were formulated as aqueous solution in $30 \% \mathrm{HP} \beta \mathrm{CD}$ starting from a $5 \%$ stock solution in DMSO. For the oral route, compounds were either suspended in $0.5 \%$ methyl cellulose, dissolved in PEG400, or given as capsules containing either mannitol or a 4:1 mixture of Cremophor RH40 and lauroglycol.

Serial blood samples of $0.25 \mathrm{ml}$ (rats) or $2 \mathrm{ml}$ (dogs) were taken over a period of 24 hours and transferred into vials fortified with EDTA as anticoagulant. Blood samples after oral dosing to rats were taken under light isoflurane anesthesia. Plasma was generated by centrifugation and stored at $-20^{\circ} \mathrm{C}$ pending analysis.

Pharmacokinetic parameters were estimated using noncompartmental analysis within the Phoenix software package (version 6.4; Pharsight Corporation, Cary, NC). Area under the plasma concentration versus time curve extrapolated to infinity $\left(\mathrm{AUC}_{0-\mathrm{inf}}\right)$ was accepted if the percentage of area extrapolated to infinity $\left(\right.$ AUC $_{\%}$ extp $)$ did not exceed $20 \%$, otherwise area under the plasma concentration versus time curve up to the last measurable concentration $\left(\mathrm{AUC}_{0-\text { last }}\right)$ was reported.

Analytical Methods. Samples from in vitro and in vivo experiments were fortified with 3-6 volume equivalents of methanol containing a close structural analog as internal standard, and proteins were removed by centrifugation at $3220 \mathrm{~g}$ for 20 minutes at $4^{\circ} \mathrm{C}$. If required, supernatants were diluted with $1 \%$ aqueous formic acid or a 1:1 mixture of acetonitrile and $1 \%$ aqueous formic acid prior to quantification by liquid chromatography coupled to mass spectrometry (LC-MS/MS) on API5000 or API5500 mass spectrometers (AB SCIEX, Concord, Ontario, Canada) in selected reaction monitoring mode. Chromatographic separation was achieved on Phenomenex Luna C8, C18, Gemini C18 or Synergy Polar RP columns (4-5 $\mu \mathrm{m}, 2.0 \times 20 \mathrm{~mm}$ internal diameter) operated at room temperature with a flow rate of $0.6 \mathrm{ml} / \mathrm{min}$, using a linear gradient starting from 5 to $10 \%$ mobile phase $\mathrm{B}$ and a run time of 0.95 minutes. Mobile phases were $0.1 \%$ aqueous formic acid or $5 \mathrm{mM}$ ammonium formate ( $\mathrm{pH} 9$, phase $\mathrm{A}$ ) and acetonitrile or methanol (phase B).

\section{TABLE 3}

Brain partitioning of orexin receptor antagonists in Wistar rats after oral dosing $^{a}$

\begin{tabular}{|c|c|c|c|c|c|c|}
\hline \multirow{2}{*}{ Compound } & \multirow{2}{*}{$\operatorname{Dose}^{b}$} & \multicolumn{2}{|c|}{ Total } & \multicolumn{2}{|c|}{ Unboundb } & \multirow{2}{*}{ Ratio } \\
\hline & & Brain & Plasma & Brain & Plasma & \\
\hline \multirow{3}{*}{ ACT-541468 } & $m g / k g$ & $n M$ & $n M$ & $n M$ & $n M$ & \\
\hline & 30 & 665 & 685 & 6.65 & 19.2 & 0.3 \\
\hline & 100 & 4010 & 2840 & 40.1 & 79.5 & 0.5 \\
\hline \multirow[t]{2}{*}{ ACT-605143 } & 30 & 154 & 494 & 1.23 & 5.93 & 0.2 \\
\hline & 100 & 2250 & 1830 & 18.0 & 22.0 & 0.8 \\
\hline \multirow[t]{2}{*}{ ACT-658090 } & 30 & 614 & 1050 & 4.30 & 9.45 & 0.5 \\
\hline & 100 & 12000 & 7270 & 84.0 & 65.4 & 1.3 \\
\hline
\end{tabular}

${ }^{a}$ Geometric mean brain and plasma concentrations were determined at 3 hours postdose $(n=3-4)$

${ }^{b}$ Formulated in PEG400; unbound concentrations in the plasma and brain were calculated using the binding at $1 \mu \mathrm{M}$ data in Table 7 . 
active wake quiet wake non-REM $\square$ REM

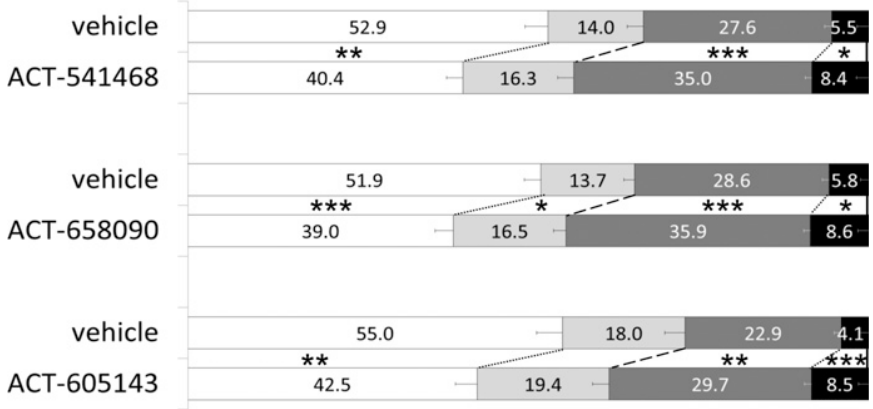

Fig. 3. Effect of benzimidazole DORAs on sleep/wake stages at $30 \mathrm{mg} / \mathrm{kg}$ in telemetrized rats. Effects of ACT-541468, ACT-658090, and ACT605143 during the first 6 hours of the night-active period in telemetrized male Wistar rats (\% of total time). Data are expressed as mean \pm S.E.M., $n=8$ per group. $* P<0.05,{ }^{*} P<0.01$, $* * * P<0.001$ compared with matched vehicle-treated rats.

Population-Based Pharmacokinetic Modeling. Simcyp Population-based ADME Simulator (version 15; Sheffield, UK) was used for PBPK modeling, and simulation PBPK models were built on the basis of physicochemical, binding, permeability and metabolic stability data (Table 7; Supplementary Materials for experimental details). Oral absorption was modeled using the advanced dissolution, absorption, and metabolism (ADAM) model within Simcyp. Compounds were modeled as a solid formulation in immediate-release capsules for dog and human or as suspension for rat, using the diffusion-layer model of Wang and Flanagan (Jamei et al., 2009) to calculate the rate of dissolution from fine particles with an assumed diameter of $1 \mu \mathrm{m}$. The effect of bile salts upon dissolution and solubility was considered, matching the measured solubility in fasted state (FaSSIF) and fed state (FeSSIF) simulated intestinal fluids. Default values for particle density of $1.2 \mathrm{~g} / \mathrm{ml}$, a supersaturation ratio of 10 , a precipitation rate constant of 15 minutes, and a diffusion layer thickness of $30 \mu \mathrm{m}$ were assumed. A full PBPK, perfusion-limited distribution model was applied using method 2 within Simcyp, with an assumed tissue-to-plasma partition coefficient $\left(\mathrm{K}_{\mathrm{p}}\right)$ scalar of 0.5 (Rodgers and Rowland, 2007; de Kanter et al., 2016). Elimination was assumed to be driven by CYP3A4-mediated metabolism, on the basis of evidence for almorexant (Dingemanse et al., 2014), suvorexant (Cui et al., 2016), and ACT-541468 (A.T., unpublished observation) using the well-stirred liver and ADAM gut model with fraction unbound in the gut $\left(f_{u, g u t}\right)$ assumed to be 0.01 . A factor of 2 was used to correct for the underprediction of in vitro-to-in vivo total plasma clearance (CL). Thus, the model was populated with measured intrinsic clearance $\left(\mathrm{CL}_{\text {int }}\right)$ values from rat, dog, or human liver microsomes, set to occur by hepatic and intestinal cyp3a (rat), cyp3a12 (dog), or CYP3A4 (human), multiplied by 2 , and corrected for nonspecific assay binding [fraction unbound in liver microsomes $\left(f_{u, m i c}\right)$, Table 7]. $\mathrm{OX}_{2}$ occupancy was estimated using predicted unbound brain concentration versus time profiles, mean unbound $\mathrm{K}_{\mathrm{b}}$ on the $\mathrm{OX}_{2}$ receptor (Tables 1 and 7), and a sigmoid $\mathrm{E}_{\max }$ model with an $\mathrm{E}_{\max }$ of $100 \%$ and a Hill slope of 1.

$$
\mathrm{OX}_{2} \text { occupancy }=\frac{E_{\max }[\text { unbound brain concentration }]}{K_{b}+[\text { unbound brain concentration }]}
$$

Free distribution of unbound drug between plasma and brain was assumed, as supported by the physicochemical properties of all compounds and the absence of relevant $\mathrm{P}$-glycoprotein and breast cancer resistance protein-mediated efflux (A.T., unpublished observation).

Ten virtual trials of 10 subjects each were simulated in a male, healthy volunteer population with an age range of 18-45 years. Variation of all physiologic parameters was on the basis of the default variation in the healthy volunteer population database used in Simcyp.

Brain Partitioning in the Rat. Brain and plasma concentrations were determined 3 hours following oral administration at 30 and
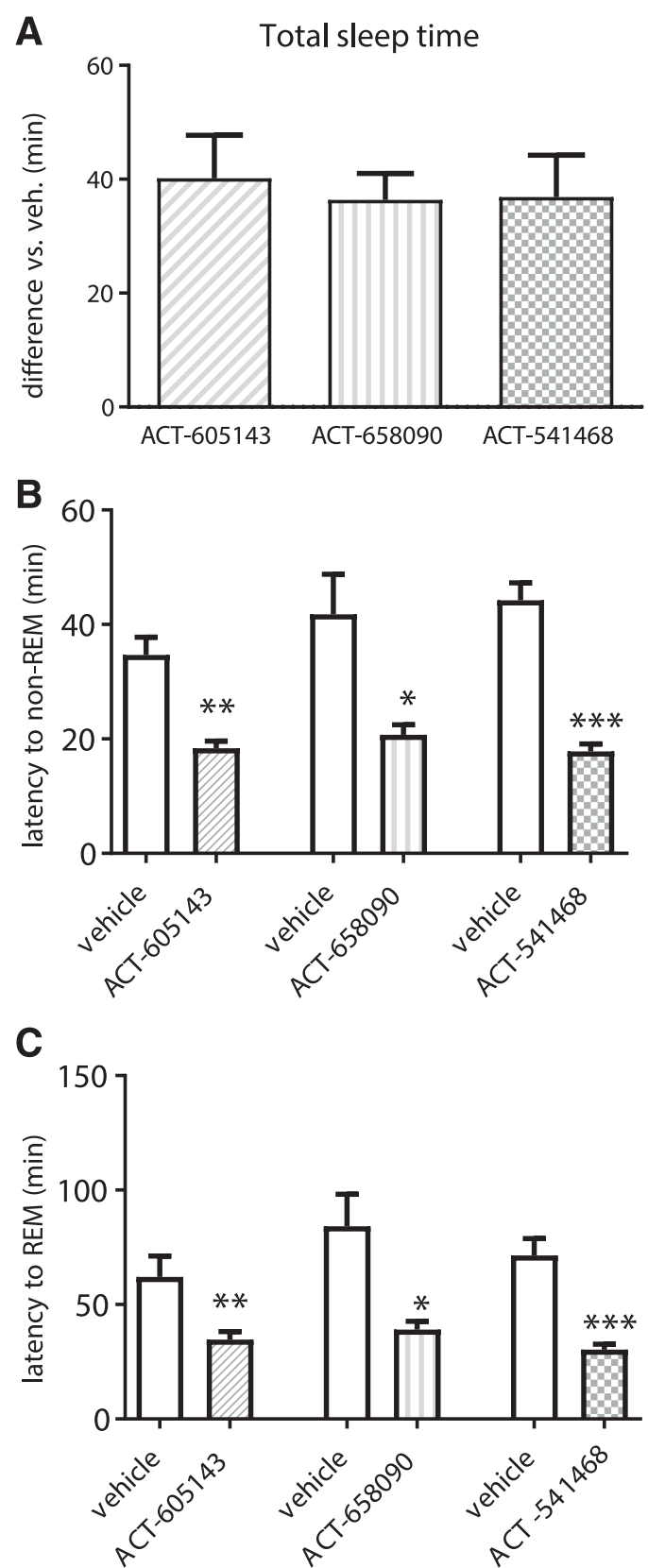

Fig. 4. Effect of benzimidazole DORAs on total sleep time (A), latency to non-REM (B), and latency to REM sleep (C) at $30 \mathrm{mg} / \mathrm{kg}$ in telemetrized rats. Effects of ACT-541468, ACT-658090, and ACT-605143 on (A) total sleep time during the first 6 hours of the night-active period (difference versus vehicle in minutes for all parameters), (B) on latency to persistent non-REM sleep (in minutes, first episode of at least 60 seconds), and (C) latency to persistent REM sleep (in minutes, first episode of at least 30 seconds) in telemetrized male Wistar rats. Data are expressed as mean \pm SEM, $n=8$ per group, ${ }^{*} P<0.05,{ }^{*} P<<0.01,{ }^{* * *} P<0.001$ compared with matched vehicle-treated rats.

$100 \mathrm{mg} / \mathrm{kg}$ to rats ( $n=3-4$ per group) under license no.KV-BL-426. All compounds were formulated as solutions in PEG400. Blood was collected from the vena cava caudalis into plastic tubes containing EDTA as anticoagulant and centrifuged to yield plasma. Brain was collected after cardiac perfusion of $10 \mathrm{ml} \mathrm{NaCl} 0.9 \%$. Brain tissue was then homogenized with 1 volume equivalent of cold phosphate buffer (pH 7.4), and compounds were extracted with methanol. Compound concentrations in plasma and brain were determined using LC-MS/MS as described above. 
Telemetric Sleep/Wake Cycle Evaluation in Rats. Sleep/ wake cycles were evaluated on the basis of electroencephalography/ electromyography (EEG/EMG) and home-cage activity recorded in individually housed Wistar rats under free-moving conditions under license no.KV-BL-205. Rats (250-350 g, 6-8 weeks of age) were equipped with telemetric transmitters (TL11M2-F20-EET; Data Science International, St. Paul, MN) that allowed the noninvasive detection of EEG/EMG and activity via signal transmission to a receiver. The surgical transmitter implantation was performed under aseptic conditions. A preoperative analgesia (buprenorphine $0.015 \mathrm{mg} / \mathrm{kg}$ s.c.) was administered 30 minutes before anesthesia. The entire surgical implantation was performed under general anesthesia [isoflurane inhalation (1-5\% vol.) initiated in an anesthetic chamber]. The rat was placed and secured in a stereotaxic apparatus. The body of the transmitter was placed subcutaneously along the dorsal flank of the rat with the leads routed subcutaneously to an incision accessing the cranium. For EEG recordings, two trepanations were placed in the skull, $2 \mathrm{~mm}$ from either side of the midline and $2 \mathrm{~mm}$ anterior to the lambda suture for placement of one differential pair of electrodes. Two other superficial trepanations were drilled for screws as support for cementing the electrodes. The EMG leads were inserted in either side of the muscles of the neck and sutured into place. After surgery, rats recovered from anesthesia in a chamber equipped with a heating pad at $37^{\circ} \mathrm{C}$. They were then housed individually and received analgesia with $0.015 \mathrm{mg} / \mathrm{kg}$ s.c. of buprenorphine B.I.D. for the first 2 days of the 2 -week postsurgery recovery period. Before the experiment, rats were acclimatized for 3 days in their home cages placed in ventilated sound-attenuating boxes, on a regular 12-hour light/dark cycle. Experiments used a "crossover" design, i.e., each animal was alternatively treated with a test compound and the vehicle, with at least 72 hours between administrations. Treatments were administered orally (gavage) at the transition between the day and the night phase. Each telemetric recording covered a 24 -hour "baseline" period preceding the treatment, the 12-hour night period immediately following the administration of treatment, and a 36 -hour recovery (washout) period. The recordings were split into a sequence of equal intervals of user-defined length (10 seconds). Sleep and wake stages (active wake, quiet wake, nonREM sleep, or REM sleep) were assigned to each interval automatically using the Somnologica Science software (Medcare; Embla Systems Ltd., Thornton, CO) on the basis of frequency estimation for EEG, amplitude discrimination for the EMG, and the locomotor activity, as follows. Wake was characterized by low-amplitude EEG activity with relatively greater power in the higher frequency bands, such as alpha-band $(10-13 \mathrm{~Hz})$, accompanied by moderate to high levels of EMG activity. Active and quiet wake were distinguished on the basis of the locomotor activity and the amplitude of the EMG. Non-REM sleep was defined by highamplitude EEG activity with greater power in the delta frequency band $(0.5-5 \mathrm{~Hz})$ and low EMG activity. REM sleep was characterized by low-amplitude EEG activity focused in the theta frequency band $(6-9 \mathrm{~Hz})$ and no EMG activity. Data were analyzed by two-tailed paired Student's $t$ test or one-way analysis of variance (ANOVA) followed by the posthoc Tukey's multiple comparisons test, using GraphPad Prism (GraphPad Software). Differences were considered statistically significant at $P<0.05$.

PK and PD Assessments of ACT-541468 in Healthy Subjects. The single-dose pharmacokinetic profile of ACT-541468 after daytime and night-time administration was assessed in the two single-center, double-blind, placebo-controlled, randomized studies AC-078-101 (NCT02919319) and AC-078-102 (NCT02571855). Both trials were conducted in full compliance with the principles of the Declaration of Helsinki, and study protocols were approved by independent Ethics Committees. Detailed information about study endpoints and inclusion and exclusion criteria are available at www.clinicaltrials.gov. For daytime pharmacokinetic assessments, eight healthy male subjects received either placebo $(n=2)$ or ACT-541468 $(n=6)$ at doses of 5, 25, 50,100 , and $200 \mathrm{mg}$, given in the morning after overnight fasting. Blood samples were collected over a period of 96 hours postdose, plasma was
TABLE 4

Observed and simulated mean pharmacokinetic parameters of orexin receptor antagonists after oral dosing to Wistar rats and Beagle $\operatorname{dogs}^{a}$

\begin{tabular}{|c|c|c|c|c|c|c|}
\hline Compound & Dose & & $\mathrm{AUC}_{0-\text { last }}$ & $\mathrm{C}_{\max }$ & $\mathrm{T}_{\max }$ & $\mathrm{F}$ \\
\hline & $m g / k g$ & & $n M \cdot h$ & $n M$ & $h$ & $\%$ \\
\hline Rat & & & & & & \\
\hline \multirow[t]{3}{*}{ ACT-541468 } & 10 & Observed & 412 & 386 & 0.5 & 9 \\
\hline & & Simulated & 1376 & 876 & 0.6 & 39 \\
\hline & $30^{b}$ & Observed & 2950 & 712 & 2.3 & 23 \\
\hline \multirow[t]{3}{*}{ ACT-605143 } & 10 & Observed & 2030 & 771 & 1.0 & 15 \\
\hline & & Simulated & 3140 & 1670 & 0.7 & 43 \\
\hline & $30^{b}$ & Observed & 6410 & 1500 & 1.0 & 18 \\
\hline \multirow[t]{3}{*}{ ACT-658090 } & 10 & Observed & 4060 & 2140 & 0.5 & 43 \\
\hline & & Simulated & 2610 & 1360 & 0.6 & 38 \\
\hline & $30^{b}$ & Observed & 7510 & 1820 & 0.5 & 27 \\
\hline \multicolumn{7}{|l|}{ Dog } \\
\hline \multirow[t]{2}{*}{ ACT-541468 } & $1.6-1.9^{c}$ & Observed & 2020 & 530 & 1.0 & 35 \\
\hline & & Simulated & 3480 & 549 & 1.2 & 40 \\
\hline \multirow[t]{2}{*}{ ACT-605143 } & $1.6-1.9^{c}$ & Observed & 4740 & 1720 & 0.5 & 28 \\
\hline & & Simulated & 4540 & 842 & 1.6 & 18 \\
\hline \multirow[t]{2}{*}{ ACT-658090 } & $1.6-1.9^{c}$ & Observed & 5610 & 1509 & 0.25 & 39 \\
\hline & & Simulated & 7510 & 978 & 1.2 & 40 \\
\hline
\end{tabular}

${ }^{a}$ All compounds were formulated as suspension in $0.5 \%$ methyl cellulose Pharmacokinetic data in the rat and dog are geometric means $(n=3)$, median is given for $\mathrm{T}_{\max }$

${ }^{b}$ Formulated in PEG400.

${ }^{c}$ Dogs received a total dose of $30 \mathrm{mg}$, bodyweight: $16-18 \mathrm{~kg}$.

separated by centrifugation, and ACT-541468 concentrations therein determined by LC-MS/MS. CL and apparent volume of distribution at steady-state $\left(\mathrm{V}_{\mathrm{ss}}\right)$ were determined using an intravenous ${ }^{14} \mathrm{C}-\mathrm{ACT}$ 541468 microdose given on top of $100 \mathrm{mg}$ oral ACT-541468 $(n=4)$. Plasma levels of radiolabeled ACT-541468 were quantified by accelerator mass spectrometry technique after chromatographic separation. Pharmacokinetic parameters after night-time administration were assessed in 6 healthy subjects who received either $25 \mathrm{mg}$ ACT-541468 $(n=4)$ or placebo $(n=2)$. PD effects were assessed in study AC-078-101 at all doses after daytime administration of ACT-541468 during the first 10 hours after dosing, using a battery of objective tests including saccadic eye movements, adaptive tracking, and body sway.

\section{Results}

\section{Inhibition of Orexin Receptor Signaling in Cellular Assays}

Almorexant and suvorexant have shown efficacy in inducing sleep in animals and humans, and, therefore, served as benchmark for the present benzimidazole series. Table 1 and Fig. 2 summarize the characterization of the three benzimidazoles ACT-541468, ACT-605143, and ACT-658090 in calcium-release assays in comparison with almorexant and suvorexant. The $\mathrm{IC}_{50}$ values measured at approximately $\mathrm{EC}_{70}$ of $\mathrm{Ox}_{\mathrm{A}}(1.6 \mathrm{nM})$ were used to calculate the apparent $\mathrm{K}_{\mathrm{b}}$ values. All five compounds behaved as potent dual antagonists, and displayed an insurmountable profile at both receptors. $K_{b}$ values ranged from 0.52 to $8.3 \mathrm{nM}$ at human $\mathrm{OX}_{1}$ receptors, and from 0.42 to $5.9 \mathrm{nM}$ at human $\mathrm{OX}_{2}$ receptors. $\mathrm{K}_{\mathrm{b}}$ values on the corresponding rat and human receptors were comparable (Supplemental Table S1). Using calcium-release assays after antagonist washout, $\mathrm{ROt}_{1 / 2}$ on $\mathrm{OX}_{1}$ was estimated to be 6-9 minutes for suvorexant and all benzimidazoles, and 22 minutes for almorexant (Table 2). On $\mathrm{OX}_{2}$, suvorexant, ACT-541468 and ACT-605143 showed ROt ${ }_{1 / 2}$ in the range of 4-6 minutes, whereas $\mathrm{ROt}_{1 / 2}$ was 13-14 minutes for ACT658090 and almorexant. In summary, the three benzimidazoles displayed in vitro receptor interaction profiles similar to those of suvorexant and almorexant. ACT-541468 was a 
TABLE 5

Proportion of non-REM and REM sleep relative to total sleep time over the first 6-hour period following oral dosing of ACT-541468, ACT-605143, or ACT-658090

\begin{tabular}{cccc}
\hline Compound & Dose & Non-REM & \\
\hline & $m g / k g$ & $\%$ & REM $^{a}$ \\
ACT-541468 & Vehicle & $79 \pm 3$ & $21 \pm 3$ \\
& 10 & $78 \pm 3$ & $22 \pm 3$ \\
& Vehicle & $84 \pm 2$ & $16 \pm 2$ \\
& 30 & $81 \pm 2$ & $19 \pm 2$ \\
& Vehicle & $85 \pm 2$ & $15 \pm 2$ \\
ACT-605143 & 100 & $80 \pm 3$ & $20 \pm 3$ \\
& Vehicle & $86 \pm 2$ & $14 \pm 2$ \\
ACT-658090 & 30 & $78 \pm 2^{b}$ & $22 \pm 2^{b}$ \\
& Vehicle & $83 \pm 2$ & $17 \pm 2$ \\
& 30 & $81 \pm 2$ & $19 \pm 2$ \\
\hline
\end{tabular}

${ }^{a}$ Data are arithmetic means \pm S.E.M. All compounds formulated in PEG400 $(n=$ 8 per dose group);

${ }^{b} P<0.001$ compared with matched vehicle-treated animals.

selective $\mathrm{OX}_{1}$ and $\mathrm{OX}_{2}$ receptor antagonist in a panel screen of more than 130 established central and peripheral pharmacological targets (A.T., unpublished observation).

\section{Pharmacology in the Rat}

Brain Penetration. Brain penetration of ACT-541468, ACT-658090, and ACT-605143 was determined 3 hours after administration of oral doses of $30 \mathrm{mg} / \mathrm{kg}$ and $100 \mathrm{mg} / \mathrm{kg}$. At $30 \mathrm{mg} / \mathrm{kg}$, mean total brain concentrations of ACT-541468 and ACT-658090 reached 665 and $614 \mathrm{nM}$ but was only $154 \mathrm{nM}$ for ACT-605143 (Table 3). Total brain levels increased in a more than dose-proportional manner at $100 \mathrm{mg} / \mathrm{kg}$, reaching 2247-12,000 nM. Correction for in vitro brain binding $\left(f_{\mathrm{u} \text {,brain }}\right.$; Table 7) yielded unbound brain concentrations around or above the $\mathrm{K}_{\mathrm{b}}$ values on rat $\mathrm{OX}_{2}$ (Supplemental Table S1), warranting further investigations in a rat sleep model.

Effect on Sleep/Wake Cycles in Rats. All three benzimidazole DORAs were tested in male Wistar rats implanted with telemetric transmitters to allow for continuous EEG/EMGbased evaluation of sleep/wake cycles in freely moving animals in their home cages. ACT-541468, ACT-605143, and ACT658090 were dosed at $30 \mathrm{mg} / \mathrm{kg}$ at the beginning of the nightactive phase, when endogenous orexin levels are rising.

All three compounds showed robust effects on sleep/wake stages over the 6-hour period postdose (Fig. 3). ACT-541468 decreased the time spent in active wake by $22 \%$ compared with vehicle-treated rats ( -45 minutes; $P=0.0068$, paired $t$ test) and increased the time spent in non-REM and REM sleep by 29 and $84 \%$ ( +26 and +10 minutes; $P=0.0009$ and $P=0.0228$ ), respectively. Latency to persistent non-REM sleep significantly decreased by $59 \%$ from 44 to 18 minutes $(P=0.0002)$, and to REM sleep by $58 \%$ from 71 to 30 minutes $(P=0.0006$, Fig. 4$)$. A similar effect was observed with ACT605143 , which decreased the time spent in active wake by $21 \%$ compared with vehicle-treated rats ( -45 minutes; $P=$ 0.0089), and increased the time spent in non-REM and REM sleep by 34 and $146 \%$ ( +24 and +16 minutes; $P=0.0092$ and $P<0.001$ ), respectively. Latency to persistent non-REM sleep significantly decreased by $49 \%$ from 35 to 18 minutes $(P=$ 0.0033 , Fig. 4), and to REM sleep by $44 \%$ from 62 to 35 minutes $(P=0.007)$. Finally, ACT-658090 decreased the time spent in active wake by $25 \%(-46$ minutes; $P<0.001)$ and increased
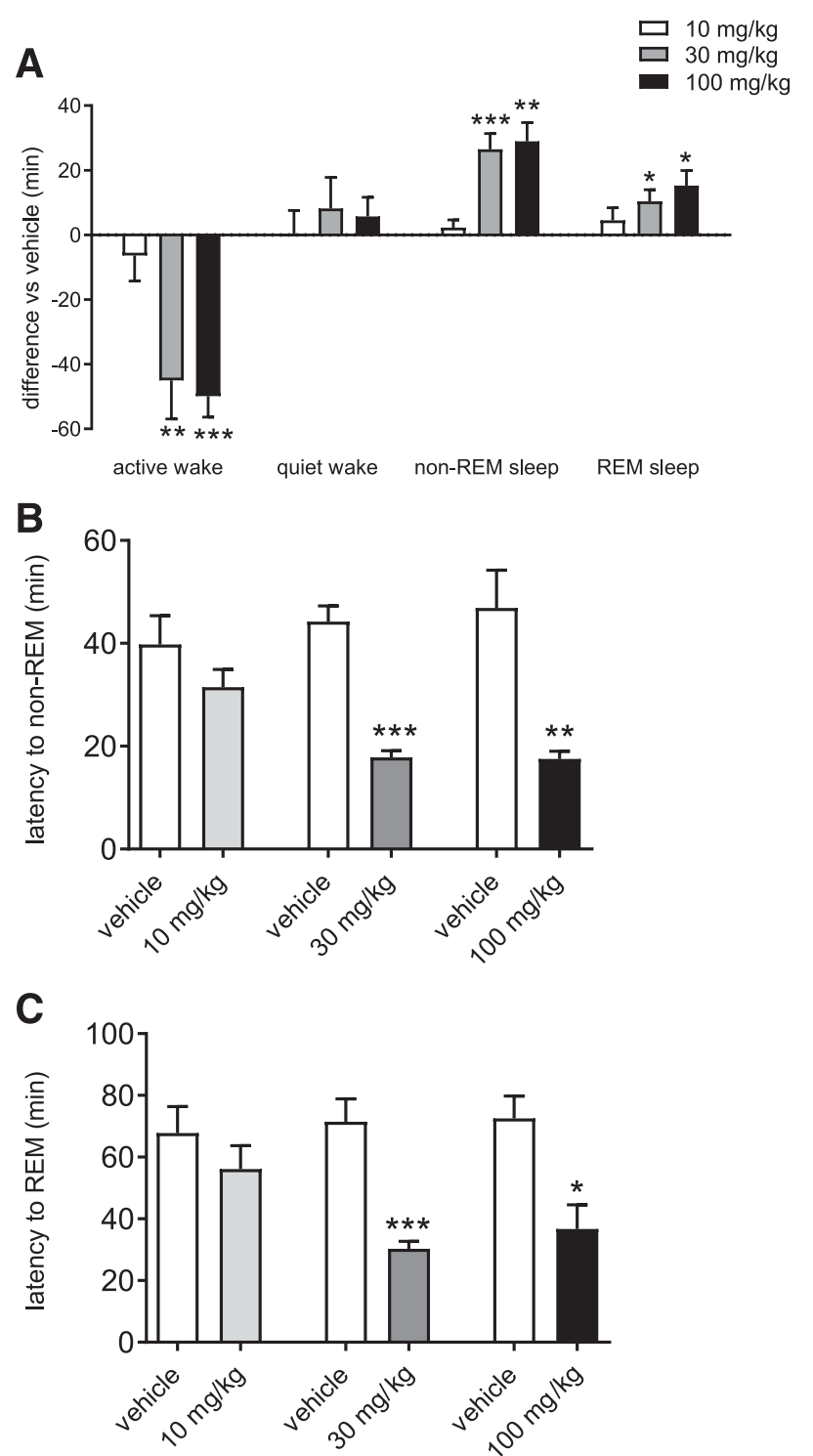

Fig. 5. Dose-response of single oral administrations of ACT-541468 on sleep/wake stages in telemetrized rats (A), latency to persistent non-REM (B) and REM sleep (C) at 10, 30, and $100 \mathrm{mg} / \mathrm{kg}$. Effect of ACT-541468 on time spent in active wake, quiet wake, non-REM, and REM sleep during the first 6 hours of the night-active period (A), on latency to persistent nonREM sleep (in minutes, first episode of at least 60 seconds, B), and on latency to persistent REM sleep (in minutes, first episode of at least 30 seconds, C) in telemetrized male Wistar rats (in minutes, difference versus matched vehicle). Data are expressed as mean \pm S.E.M., $n=8$ per group. $* P<0.05, * * P<0.01, * * * P<0.001$ compared with matched vehicle-treated rats.

the time spent in quiet wake by $21 \%$ ( +10 minutes; $P=0.0099)$. It increased the time spent in both non-REM and REM sleep by $27 \%$ and $57 \%$ ( +26 minutes, $P=0.0001$; and +10 minutes, $P=0.0127$ ), respectively. Latency to persistent non-REM sleep significantly decreased by $50 \%$ from 42 to 21 minutes $(P=0.030)$, and to REM sleep by $54 \%$ from 84 to 39 minutes $(P=0.032)$. Efficacy of the 3 benzimidazole DORAs over the 6-hour period following a $30 \mathrm{mg} / \mathrm{kg}$ dose was similar (Fig. 4). The increase in total sleep time over the 6 -hour period was between 36 and 40 minutes for all compounds and differences between compounds were not statistically significant $(P=0.9087$, one-way ANOVA). Drug exposure, expressed 
as $\mathrm{AUC}_{0-\text { last }}$, was also similar, within a 2.5 -fold range from 2950-7510 nM.h (Table 4).

The dose response of ACT-541468 in the rat sleep model was characterized at 10, 30 and $100 \mathrm{mg} / \mathrm{kg}$ (Fig. 5). ACT-541468 dose-dependently impacted sleep/wake parameters. Over the 6-hour time period following administration, time spent in active wake decreased by $6-50$ minutes, and time spent in non-REM and REM sleep increased by 2-29 minutes and 5-15 minutes, respectively. The lowest dose giving significant effects was $30 \mathrm{mg} / \mathrm{kg}$. In the vehicle group, latency to persistent non-REM sleep varied from 40 to 47 minutes, depending on the group. Compared with vehicle, ACT-541468 significantly decreased the latency to persistent non-REM sleep to 18 minutes at $30(P=0.0002)$ or $100 \mathrm{mg} / \mathrm{kg}(P=0.0079)$, and the latency to persistent REM sleep down to 30 minutes and 37 minutes at $30 \mathrm{mg} / \mathrm{kg}(P=0.0006)$ and $100 \mathrm{mg} / \mathrm{kg}(P=0.014)$, respectively.

In the vehicle-treated animals, the proportion of non-REM and REM sleep relative to total sleep time varied between 79-86\% for non-REM sleep, and between $14-21 \%$ for REM sleep (Table 5). The proportion of non-REM and REM sleep did not change in a statistically significant manner for ACT-541468 at $30 \mathrm{mg} / \mathrm{kg}(P=0.15)$ or $100 \mathrm{mg} / \mathrm{kg}(P=0.59)$, or for ACT-658090 at $30 \mathrm{mg} / \mathrm{kg}(P=0.27)$. In contrast, the time spent in non-REM sleep significantly decreased from 86 to $78 \%(P=0.00074)$ for ACT- 605143 at $30 \mathrm{mg} / \mathrm{kg}$.

\section{Pharmacokinetics in Rat and Dog}

Pharmacokinetics of all three benzimidazole compounds were characterized in male rats and dogs to generate a database for validation of the respective PBPK models. Pharmacokinetic results after oral and intravenous administration are summarized in Tables 4 and 6, respectively. Plasma clearance of ACT605143 and ACT-658090 in the rat was $32-36 \mathrm{ml} / \mathrm{min}$ per kilogram, and $85 \mathrm{ml} / \mathrm{min}$ per kilogram for ACT-541468. After correction for blood/plasma partitioning (Table 7), blood clearance of all three compounds was in a narrow range of $36-45 \mathrm{ml} / \mathrm{min}$ per kilogram, i.e., ca. $51-64 \%$ of liver blood flow in the rat. Plasma and blood clearances in the dog were $3.9-9.5 \mathrm{ml} / \mathrm{min}$ per kilogram and $6.5-15 \mathrm{ml} / \mathrm{min}$ per kilogram, respectively, the latter corresponding to $44-48 \%$ of liver blood flow for ACT-541468 and ACT- 605143 but only $21 \%$ for ACT-658090. $\mathrm{V}_{\mathrm{ss}}$ in the rat was in large excess of total body water, indicating significant drug distribution into tissues: 3.2 and 3.9 l per kilogram for ACT-541468 and ACT-658090, but only $0.8 \mathrm{l} / \mathrm{kg}$ for ACT605143. $\mathrm{V}_{\mathrm{ss}}$ in the dog was in a more narrow range, between $1.1-2.4 \mathrm{l} / \mathrm{kg}$.

Oral absorption of all compounds was rapid in rat and dog, with peak plasma concentrations $\left(\mathrm{C}_{\text {max }}\right)$ being reached within 0.25-2.3 hours (Table 4). Oral exposures $\left(\mathrm{AUC}_{0-\text { last }}\right)$ in the rat at $10 \mathrm{mg} / \mathrm{kg}$ varied by about 10 -fold, from $412 \mathrm{nM} \cdot \mathrm{h}$ for ACT-541468 to $4060 \mathrm{nM} \cdot \mathrm{h}$ for ACT-658090, which was also reflected in their different oral bioavailability $(\mathrm{F})$ of 9 versus $43 \%$. Smaller differences in $\mathrm{AUC}_{0-\text { last }}$ were observed in the dog, with $2020 \mathrm{nM} \cdot \mathrm{h}$ for ACT-541468 and $5610 \mathrm{nM} \cdot \mathrm{h}$ for ACT658090. Similar trends were evident for $\mathrm{C}_{\max }$ in both species (Table 4).

\section{PBPK Model Development for Predicting Human PK Profiles}

PBPK models for the benzimidazole DORAs ACT-541468, ACT-605143, and ACT-658090 were built on the basis of in silico and biochemical data (Table 7), as outlined in Fig. 6. PBPK models were initially developed for rat and dog and validated against observed PK data in both species. All three PBPK models consistently overpredicted observed $V_{\mathrm{ss}}$. Therefore, a $\mathrm{K}_{\mathrm{p}}$ scalar of 0.5 was applied to empirically correct the predicted tissue-to-plasma ratios in all simulated tissues. In contrast, CL predictions underestimated observed values by approximately 2 -fold, and microsomal $\mathrm{CL}_{\text {int }}$ was therefore multiplied by 2 in the PBPK models. The simulated pharmacokinetic parameters of these refined PBPK models after intravenous and oral dosing in rat and dog were considered similar enough to the observed values to construct the corresponding human PBPK models (Table 4 and Table 6). The simulated plasma concentration versus time profiles and derived pharmacokinetic parameters of the three benzimidazoles in healthy volunteers at a dose of $25 \mathrm{mg}$ are shown in Fig. 7A. At this dose, the predicted fraction absorbed was $96-100 \%$ and not sensitive to the supersaturation ratio (1-100) or precipitation constant (0.4-40). Among the three compounds, ACT-541468 showed the fastest simulated oral

TABLE 6

Observed and simulated mean systemic pharmacokinetic parameters of orexin antagonists in rats, dogs, and healthy subjects ${ }^{a}$

\begin{tabular}{|c|c|c|c|c|c|}
\hline \multirow{2}{*}{ Species } & \multirow{2}{*}{ Compound } & \multicolumn{2}{|c|}{ CL } & \multicolumn{2}{|c|}{$\mathrm{V}_{\mathrm{ss}}$} \\
\hline & & Observed & Simulated & Observed & Simulated \\
\hline & & $\mathrm{ml} / \mathrm{min} / \mathrm{kg}$ & $\mathrm{ml} / \mathrm{min} / \mathrm{kg}$ & $\mathrm{l} / \mathrm{kg}$ & $\mathrm{l} / \mathrm{kg}$ \\
\hline \multirow[t]{3}{*}{ Rat } & ACT-541468 & 85 & 104 & 3.9 & 2.5 \\
\hline & ACT- 605143 & 32 & 51 & 0.8 & 1.7 \\
\hline & ACT- 658090 & 36 & 50 & 3.2 & 2.5 \\
\hline \multirow[t]{3}{*}{ Dog } & ACT-541468 & 9.5 & 15 & 2.4 & 2.9 \\
\hline & ACT- 605143 & 7.4 & 7.7 & 1.1 & 2.4 \\
\hline & ACT- 658090 & 3.9 & 4.9 & 2.2 & 3.3 \\
\hline \multirow[t]{5}{*}{ Human } & Almorexant & $8.9^{b}$ & 8.1 & $8.5^{b}$ & 8.9 \\
\hline & Suvorexant & $0.8^{c}$ & 1.0 & $0.6^{c}$ & 0.4 \\
\hline & ACT-541468 & 1.0 & 1.2 & 0.4 & 0.5 \\
\hline & ACT-605143 & N/A & 0.2 & N/A & 0.2 \\
\hline & ACT-658090 & N/A & 0.1 & N/A & 0.2 \\
\hline
\end{tabular}

${ }^{a}$ Observed pharmacokinetic data are geometric means from $\mathrm{n}=3$ for rat and dog, and $\mathrm{n}=4-20$ for healthy human subjects; geometric mean data are given for simulated values.

${ }^{b}$ Calculated from (Hoch et al., 2012) for a body weight of $80 \mathrm{~kg}$.

${ }^{c}$ Calculated from (TGA, 2014) for a body weight of $80 \mathrm{~kg}$. 
TABLE 7

Biochemical and physicochemical data for PBPK model development

Biochemical data are means of at least triplicate experiments.

\begin{tabular}{|c|c|c|c|}
\hline Parameter & ACT-541468 & ACT-605143 & ACT-658090 \\
\hline $\log \mathrm{D}$ & 3.8 & 4.0 & 4.3 \\
\hline $\mathrm{pK}_{\mathrm{a}}$ & 4.2 & 4.0 & 4.2 \\
\hline Molecular weight $(\mathrm{g} / \mathrm{mol})$ & 451 & 449 & 490 \\
\hline Solubility FaSSIF $(\mu \mathrm{g} / \mathrm{ml})^{a, f}$ & 79 & 76 & $196^{d}$ \\
\hline Solubility FeSSIF $(\mu \mathrm{g} / \mathrm{ml})^{b}$ & 256 & 83 & $653^{d}$ \\
\hline Solubility PB $(\mu \mathrm{g} / \mathrm{ml})^{c}$ & 14 & $18^{e}$ & $32^{d}$ \\
\hline $\mathrm{f}_{\mathrm{u}, \mathrm{OX} 2 \text { assay }}$ & 0.79 & 0.80 & 0.69 \\
\hline $\mathrm{f}_{\mathrm{u}, \text { brain }}$ & 0.010 & 0.008 & 0.007 \\
\hline$f_{u, \operatorname{mic}}$ & 0.41 & 0.34 & 0.29 \\
\hline Permeability (A-to-B, $10^{-6} \mathrm{~cm} / \mathrm{sec}$ ) & 22.6 & 15.4 & 34.3 \\
\hline $\mathrm{CL}_{\text {int }}(\mu \mathrm{l} / \mathrm{min} / \mathrm{mg}$, rat $)$ & 990 & 835 & 988 \\
\hline $\mathrm{f}_{\mathrm{u}, \text { plasma }}(\mathrm{rat})$ & 0.028 & 0.012 & 0.009 \\
\hline Blood/plasma ratio (rat) & 2.1 & 0.9 & 0.8 \\
\hline $\mathrm{CL}_{\text {int }}(\mu \mathrm{l} / \mathrm{min} / \mathrm{mg}, \operatorname{dog})$ & 235 & 212 & 89 \\
\hline $\mathrm{f}_{\mathrm{u}, \text { plasma }}(\mathrm{dog})$ & 0.024 & 0.012 & 0.008 \\
\hline Blood/plasma ratio (dog) & 0.7 & 0.5 & 0.6 \\
\hline $\mathrm{CL}_{\text {int }}(\mu \mathrm{l} / \mathrm{min} / \mathrm{mg}$, human $)$ & 138 & 149 & 69 \\
\hline $\mathrm{f}_{\mathrm{u}, \text { plasma }}($ human) & 0.0013 & 0.0004 & 0.0010 \\
\hline Blood/plasma ratio (human) & 0.5 & 0.7 & 0.7 \\
\hline
\end{tabular}

$\mathrm{f}_{\mathrm{u}, \text { brain }}$, fraction unbound in the brain; $\mathrm{f}_{\mathrm{u} \text {,gut }}$, fraction unbound in the gut; $\mathrm{f}_{\mathrm{u}, \text { mic }}$, fraction unbound in liver microsomes; $\mathrm{f}_{\mathrm{u}}$ $\mathrm{Ox} 2$ assay, fraction unbound in $\mathrm{OX}_{2}$ binding assay; $\mathrm{f}_{\mathrm{u} \text {,plasma }}$, fraction unbound in plasma.

${ }^{a}$ FaSSIF, simulated intestinal fluid at fasted state, pH 6.5 and $37^{\circ} \mathrm{C}$

${ }^{b} \mathrm{FeSSIF}$, simulated intestinal fluid at fed state, $\mathrm{pH} 5.0$ and $37^{\circ} \mathrm{C}$.

${ }^{c} \mathrm{~PB}$, phosphate buffer, $\mathrm{pH} 7.0-7.4,25^{\circ} \mathrm{C}$.

${ }^{d}$ Noncrystalline material.

${ }^{e}$ At $37^{\circ} \mathrm{C}$.

Data of hydrochloride salt.

absorption with a time to reach peak plasma concentration $\left(\mathrm{T}_{\max }\right)$ of 2 hours, the shortest initial half-life of 4.3 hours, and the lowest $\mathrm{C}_{\max }$ and $\mathrm{AUC}_{0-24 \mathrm{~h}}$ of $814 \mathrm{nM}$ and $6500 \mathrm{nM} \cdot \mathrm{h}$, respectively (Table 8). ACT-658090 and ACT-605143 exhibited 5.9- to 7.3-fold higher $\mathrm{AUC}_{0-24 \mathrm{~h}}$, and 2.9-3.3 times higher $\mathrm{C}_{\max }$, and reached peak plasma concentrations later than ACT541468 , with $\mathrm{T}_{\max }$ of 3.6-3.9 hours. Most important for a sleep agent, plasma levels of ACT-658090 and ACT-605143 declined with relatively long half-lives of 10.4 and 26.8 hours, resulting in significant residual drug levels at the end of the 24-hour dosing interval (Fig. 7A).

PBPK models for suvorexant and almorexant were developed using physicochemical and biochemical data (Supplemental Table S2) together with published clinical data for both compounds (Hoch et al., 2012; Sun et al., 2013; Dingemanse et al., 2014; TGA, 2014). For both, suvorexant and almorexant,

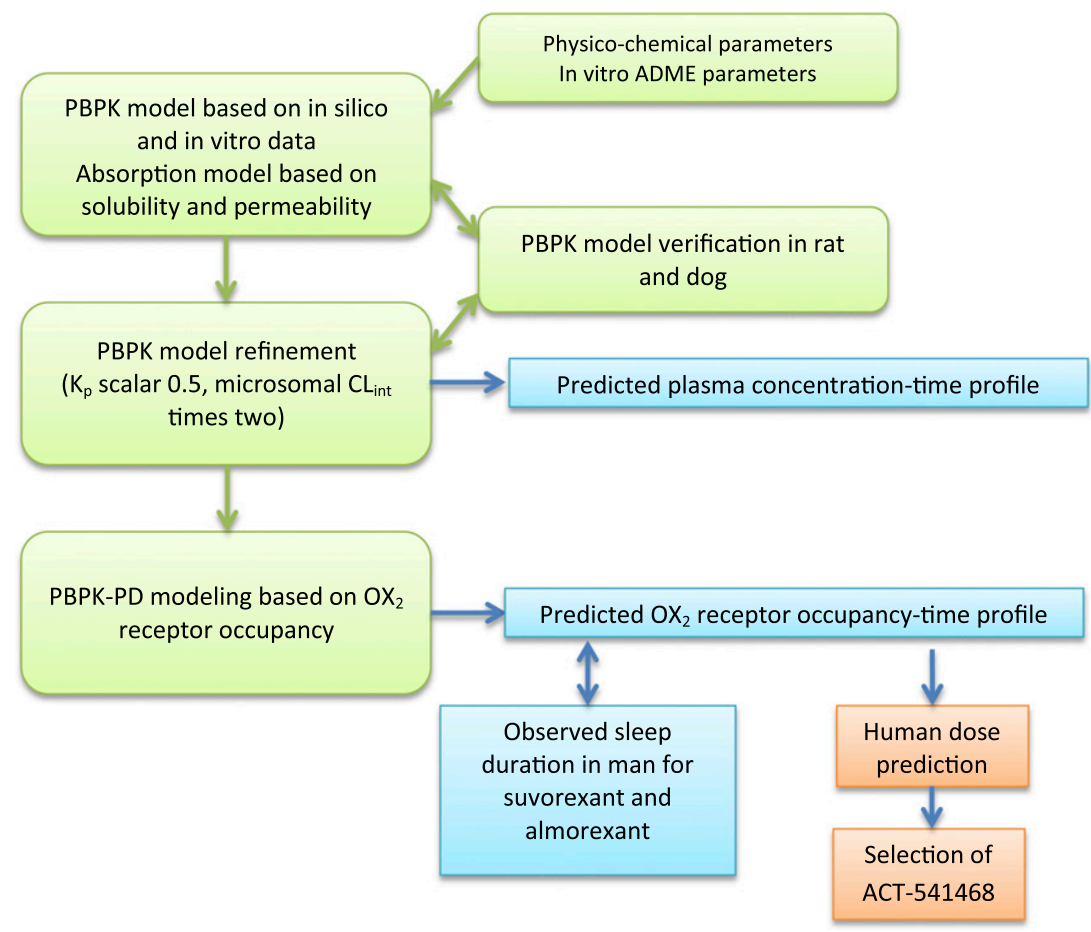

Fig. 6. PBPK and absorption model development and application. 


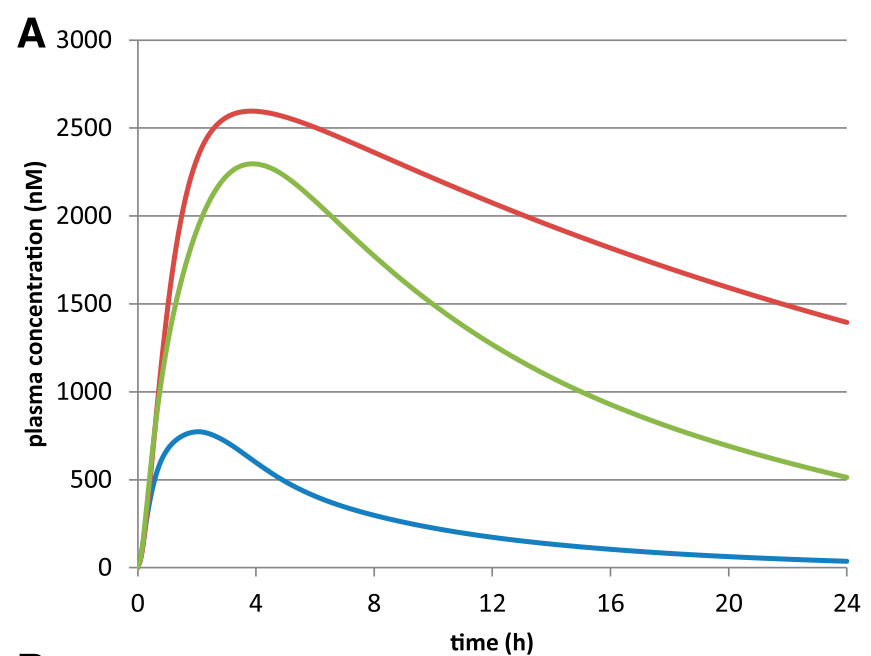

B

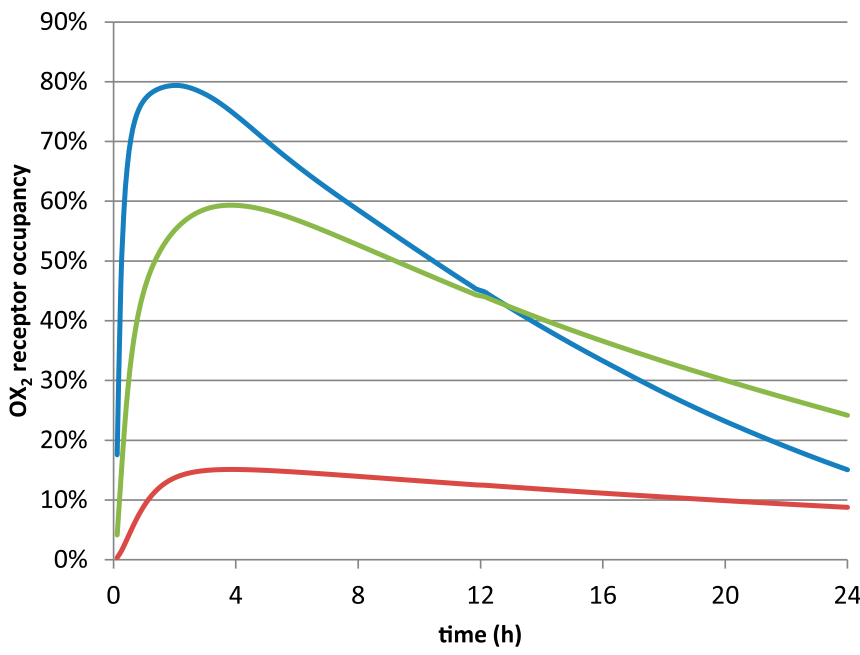

oral absorption was modeled using ADAM and cellular permeability determined in MDCKII cells. Tissue distribution of suvorexant and almorexant was modeled as described above, and elimination was modeled on the basis of published plasma clearances of $5 \mathrm{l} / \mathrm{h}$ and $43 \mathrm{l} / \mathrm{h}$, respectively (Hoch et al., 2012;

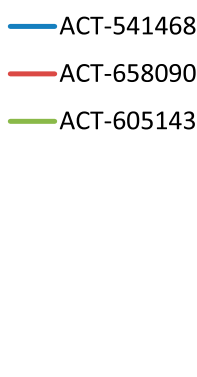

Fig. 7. Simulated geometric mean plasma concentration (A) and $\mathrm{OX}_{2}$ receptor occupancy (B) versus time profiles of ACT-541468, ACT-605143 and ACT-658090 after a $25-\mathrm{mg}$ dose given to healthy male subjects. Plasma concentration-versus-time profiles were predicted using PBPK models (A), and $\mathrm{OX}_{2}$ receptor occupancy-versustime profiles (B) were predicted on the basis of a $\mathrm{E}_{\max }$ model driven by the unbound brain concentrations of the benzimidazole compounds.

\section{-ACT-541468 \\ ACT-658090 \\ ACT-605143}

TABLE 8

TGA, 2014). Final model parameters after intravenous and oral dosing are presented in Tables $6\left(\mathrm{CL}\right.$ and $\left.\mathrm{V}_{\mathrm{ss}}\right)$ and $8\left[\mathrm{AUC}_{0-24 \mathrm{~h}}\right.$, $\mathrm{C}_{\max }, \mathrm{T}_{\max }$, initial half-life $\left.\left(\mathrm{T}_{1 / 2}\right)\right]$. The observed and simulated mean plasma concentration-time profiles of 40/50 mg suvorexant and $200 \mathrm{mg}$ almorexant are shown in Fig. 8.

Observed and simulated pharmacokinetic parameters and estimated $\mathrm{OX}_{2}$ receptor occupancies in healthy male subjects ${ }^{a}$

\begin{tabular}{cclrrrrc}
\hline Compound & Dose & Time of dosing & $\mathrm{AUC}_{0-24 \mathrm{~h}}$ & $\mathrm{C}_{\max }$ & $\mathrm{T}_{\max }$ & $\mathrm{T}_{1 / 2}{ }^{b}$ & OX $_{2}$ occupancy at 8 h \\
\hline \multirow{4}{*}{ Almorexant } & $m g$ & & $n M \cdot h$ & $n M$ & \multicolumn{1}{c}{$h$} & \multicolumn{1}{c}{$h$} & $\%$ \\
& 200 & Daytime & 747 & 182 & 1.0 & 2.7 & N/A \\
& 200 & Night-time & 620 & 74 & 4.0 & 6.4 & N/A \\
Suvorexant & 200 & Simulated & 1080 & 157 & 1.6 & 3.1 & 63 \\
& 40 & Daytime $^{c}$ & 10,500 & 1130 & 4.0 & 12.1 & N/A \\
& 50 & Night-time $^{d}$ & 8570 & 870 & 3.0 & 10.8 & N/A \\
ACT-541468 & 50 & Simulated $^{e}$ & 8990 & 750 & 3.3 & 8.7 & N/A \\
& 25 & Daytime & 5700 & 1400 & 1.0 & 3.0 & N/A \\
ACT-605143 & 25 & Night-time & 8270 & 1050 & 1.5 & 5.1 & 58 \\
ACT-658090 & 25 & Simulated & 6500 & 814 & 2.0 & 4.3 & 53 \\
& 25 & Simulated & 31,900 & 2380 & 3.9 & 10.4 & 14 \\
\hline
\end{tabular}

${ }^{a}$ Observed and simulated pharmacokinetic data are geometric means; median is given for $\mathrm{T}_{\max }$

${ }^{b}$ Half-lives were calculated on the basis of the initial decline of the plasma concentration-versus-time curves.

${ }^{c} \mathrm{AUC}$ and $\mathrm{C}_{\max }$ data were estimated on the basis of data from (Sun et al., 2013).

${ }^{d}$ Data taken from (Sun et al., 2013).

${ }^{e}$ Simulated data are for the hydrochloride salt; N/A, not applicable. 


\section{Human Dose Estimates}

PK/PD Analysis of Almorexant and Suvorexant in Rats as Basis for Human PD Threshold Concentrations. An attempt to estimate drug exposures needed to induce sleep in humans was done on the basis of a PK/PD analysis in rats. The sleep-wake pattern in rats was analyzed after treatment with almorexant and suvorexant at doses of 10,30 , and $100 \mathrm{mg} / \mathrm{kg}$ given at the beginning of the active period (lights off), together with exposure data from PK experiments in a satellite group of rats. Both compounds were inactive at $10 \mathrm{mg} / \mathrm{kg}$ (Supplemental Fig. S2), with almorexant and suvorexant plasma exposures in the first hours reaching 97 and $443 \mathrm{nM}$, respectively. At $30 \mathrm{mg} / \mathrm{kg}$, total sleep time increased significantly with both compounds to about 3-7 hours for almorexant, and about 2 hours for suvorexant (Supplemental Figs. S2 and S3) at total and unbound plasma concentrations of ca. 195 and $1.2 \mathrm{nM}$ for almorexant and ca. 890 and $3.5 \mathrm{nM}$ for suvorexant, which were regarded as PD threshold plasma concentrations in rat. Considering human plasma protein binding and the absence of potency differences at target receptors (Table 1 and Supplemental Table S1), and assuming the need for similar degrees of $\mathrm{OX}_{2}$ blockade in rats and humans, the predicted human PD threshold plasma concentrations would be $195 \mathrm{nM}$ for almorexant and $3550 \mathrm{nM}$ for suvorexant. These projected values were about 5- to 6 -fold above the exposures observed in man with sleep-inducing doses of almorexant ( $200 \mathrm{mg}$; 8-hour residual exposure of $20 \mathrm{ng} / \mathrm{ml}$ ) and suvorexant (50 mg; 8-hour residual exposure of $240 \mathrm{ng} / \mathrm{ml}$; Fig. 8). It is noteworthy, that an exact determination of sleep duration in rats is technically difficult and is a methodological limitation of this approach. Moreover, the fragmented sleep pattern in rats, i.e., alternating sleep and wake periods both in the active night and the inactive day period might render a direct translation of PD threshold concentrations from rat to humans difficult. Owing to these uncertainties, human dose predictions were performed on the basis of $\mathrm{OX}_{2}$ receptor occupancy estimates.

Orexin 2 Receptor Occupancy Estimates of Almorexant and Suvorexant in Humans. On the basis of PBPK models of almorexant and suvorexant (Table 8 and Fig. 8) and assuming $\mathrm{OX}_{2}$ blockade as the driving force for sleep maintenance, PBPK-PD models, i.e., $\mathrm{OX}_{2}$ receptor occupancy versus-time profiles, were constructed using a sigmoid $\mathrm{E}_{\max }$ model, unbound drug concentrations in brain, and the unbound $\mathrm{K}_{\mathrm{b}}$ values for $\mathrm{OX}_{2}$ inhibition shown in Table $1 . \mathrm{OX}_{2}$ receptor occupancies were then estimated at 8 hours postdose as the presumed end of the sleep period (Table 8). According to these PBPK-PD models, $200 \mathrm{mg}$ almorexant resulted in a peak $\mathrm{OX}_{2}$ receptor occupancy of $81 \%$ at 2.5 hours postdose, which declined to $63 \%$ at 8 hours postdose. Likewise, a 50-mg dose of suvorexant yielded a maximal $\mathrm{OX}_{2}$ receptor occupancy of $73 \%$ reached at 3.2 hours after drug intake, which slowly declined to $66 \%$ at 8 hours postdose.

Human Dose Estimates for Benzimidazole DORAs. The $\mathrm{OX}_{2}$ receptor occupancy versus time profiles of the three benzimidazole DORAs in healthy male subjects were derived starting from the respective PBPK models (Fig. 7A). $\mathrm{OX}_{2}$ receptor occupancy versus time profiles in brain (Fig. 7B) were then predicted on the basis of unbound brain concentrations, assuming that unbound drug in plasma readily equilibrates with brain and using the unbound $\mathrm{K}_{\mathrm{b}}$ constants on $\mathrm{OX}_{2}$ in a sigmoid $\mathrm{E}_{\max }$ model with a Hill factor of 1 . Using this approach, ACT-541468 doses were identified targeting an $\mathrm{OX}_{2}$ receptor blockade of about $65 \%$ over a period of 8 hours. As shown in
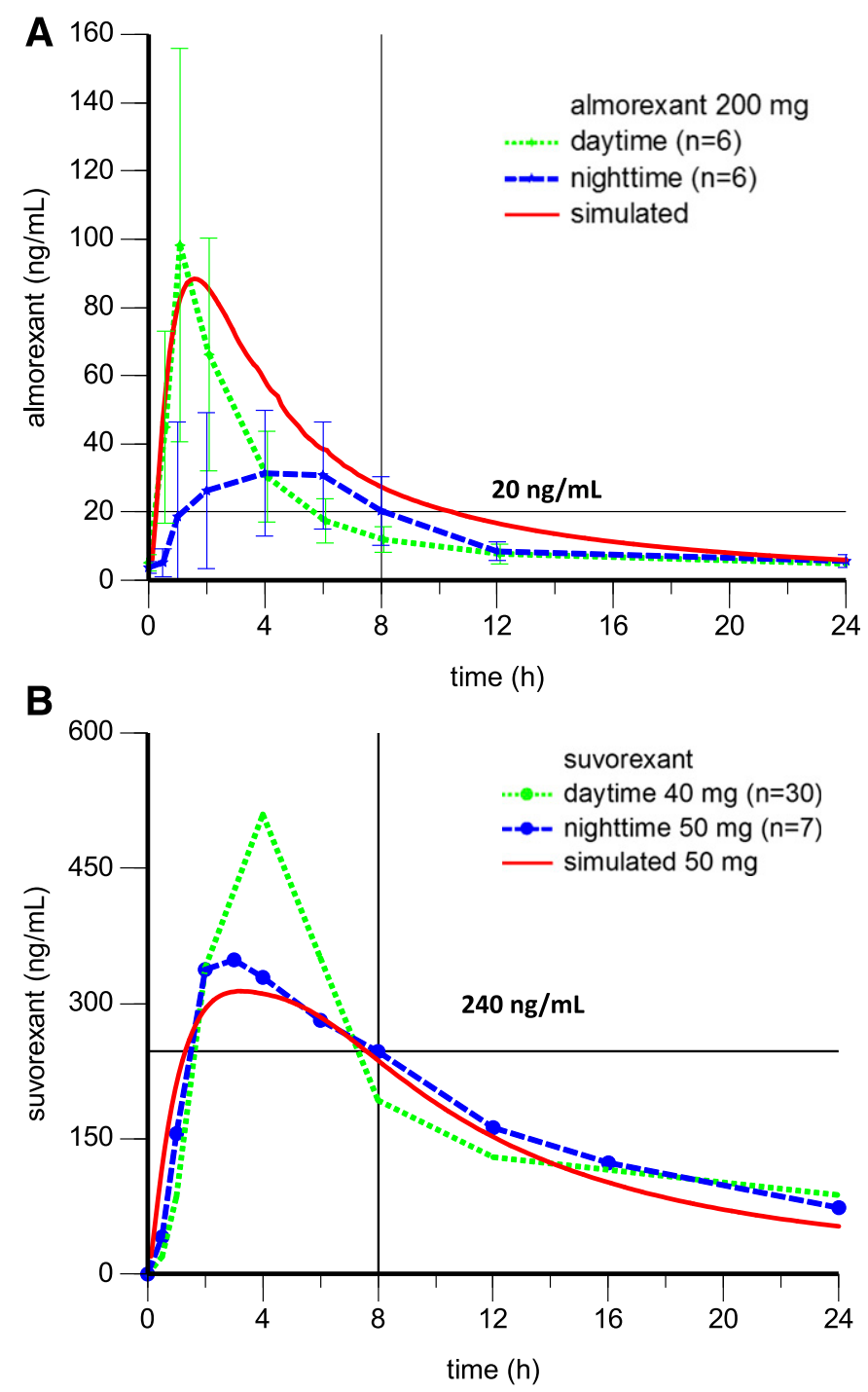

Fig. 8. Observed (daytime and night-time) and simulated geometric mean plasma concentration-versus-time plots of $200 \mathrm{mg}$ almorexant (A) and 40 or $50 \mathrm{mg}$ suvorexant (B). Plasma concentration versus time profiles were reconstructed on the basis of published data for almorexant (Hoever et al., 2012a) and suvorexant (Sun et al., 2013, 2015). Horizontal lines indicate total plasma concentrations at 8 hours after night-time administration. Data for almorexant are given as geometric mean \pm S.D. with daytime time points being shifted by +10 minutes for clarity. Data for suvorexant are given as geometric means only as no information on variability is given in the published literature.

Table 8, an ACT-541468 dose of $25 \mathrm{mg}$ resulted in a predicted $\mathrm{OX}_{2}$ receptor occupancy of $58 \%$ at 8 hours postdose. $\mathrm{OX}_{2}$ receptor occupancies estimated for ACT-605143 and ACT-658090 at 8 hours postdose at the same $25 \mathrm{mg}$ dose yielded values of 53 and $14 \%$, respectively (Table 8 ).

ACT-541468 Pharmacokinetics and Pharmacodynamics in Healthy Subjects. The pharmacokinetic and pharmacodynamic profile of ACT-541468 was assessed in healthy subjects ( $n=6$ on active, $n=2$ on placebo) after daytime administration at doses ranging from 5 to $200 \mathrm{mg}$. Night-time pharmacokinetic data were only generated for the $25 \mathrm{mg}$ dose $(n=4)$. Only data on the $25 \mathrm{mg}$ dose are reported here. Geometric mean pharmacokinetic parameters (median for $\mathrm{T}_{\text {max }}$ ) after daytime and night-time administration are summarized in Table 8 and are graphically 
depicted in Fig. 9. After daytime administration, ACT-541468 was rapidly absorbed as judged from the median $\mathrm{T}_{\max }$ of 1 hour. Peak plasma concentrations and $\mathrm{AUC}_{0-24 \mathrm{~h}}$ were $1400 \mathrm{nM}$ and $5700 \mathrm{nM} \cdot \mathrm{h}$, respectively. Oral absorption was slightly delayed to 1.5 hours after night-time dosing and peak plasma concentrations were reduced to $1050 \mathrm{nM}$. $\mathrm{AUC}_{0-24 \mathrm{~h}}$ was $8270 \mathrm{nM} \cdot \mathrm{h}$, i.e., about $45 \%$ higher compared with daytime administration. The pharmacodynamic effects of ACT-541468 were assessed during the first 10 hours after dosing using a battery of objective tests, including saccadic eye movements, adaptive tracking, and body sway. The effect of $25 \mathrm{mg}$ ACT-541468 on adaptive tracking as one of the most sensitive assessments of vigilance and attention is depicted in Fig. 10.

$\mathrm{CL}$ and $\mathrm{V}_{\mathrm{ss}}$ were determined from an intravenous ${ }^{14} \mathrm{C}-\mathrm{ACT}$ 541468 microdose given on top of $100 \mathrm{mg}$ oral ACT-541468 $(n=4)$, followed by quantification of ACT-541468 using accelerator mass spectrometry technique after chromatographic separation. Results are summarized in Table 6 and were used for the validation of the human PBPK model.

\section{Discussion}

An ideal sleep drug should mediate rapid sleep onset and sleep maintenance through major parts of the night and be devoid of next-day effects. Although sleep onset may be optimized by appropriate formulation strategies, including particle-size control or use of solubility enhancers, sleep maintenance is dependent on intrinsic factors such as the time course of target receptor blockade in the brain. Tools allowing for robust estimates of drug levels in human brain are therefore key for a successful sleep drug discovery program. Sleep models in rodent and nonrodent animal species have been conventionally used for this purpose and constitute an appropriate choice for compounds with little interspecies differences in receptor pharmacology and pharmacokinetics. Translation of animal data to man becomes challenging when interspecies differences are prominent.

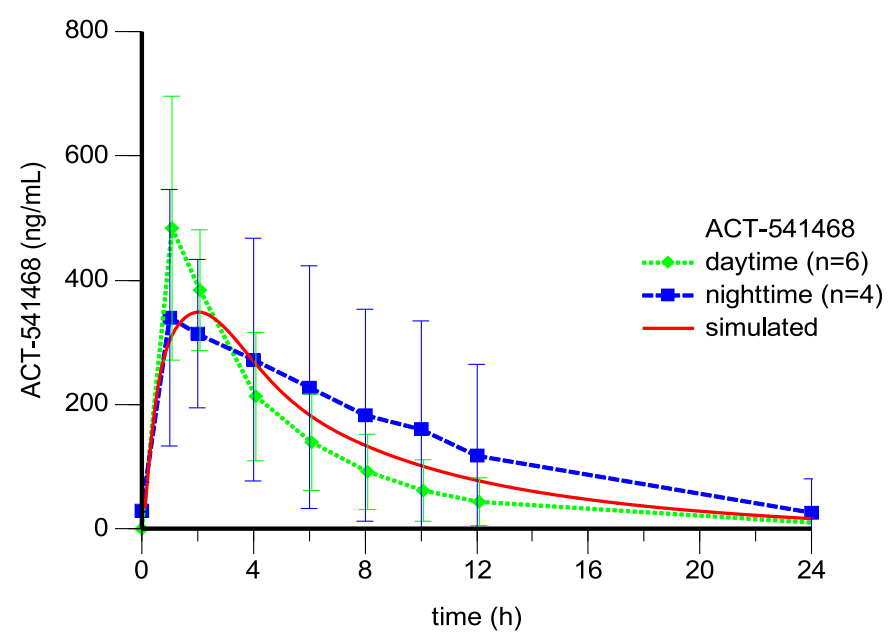

Fig. 9. Observed (daytime and night-time) and simulated geometric mean plasma concentration-versus-time profiles of ACT-541468 after a $25 \mathrm{mg}$ dose administered to healthy subjects. Plasma concentration versus-time profiles were either predicted using PBPK model (simulated) or observed in a clinical trial (daytime and night-time) (Muehlan et al., 2017). Observed data are given as geometric means \pm S.D., with daytime time points being shifted by +10 minutes for clarity.
All three benzimidazole DORAs described here fulfill the basic requirements of a sleep drug. They are potent and insurmountable antagonists of both orexin receptors showing comparable $\mathrm{K}_{\mathrm{b}}$ values on $\mathrm{OX}_{1}$ and $\mathrm{OX}_{2}$ (Table 1). In line with their physicochemical properties and the absence of relevant $\mathrm{P}$-glycoprotein efflux, they readily cross the blood-brain barrier, as evidenced by the similarity of unbound brain and plasma concentrations in rats (Table 3). A $30 \mathrm{mg} / \mathrm{kg}$ dose increased non-REM, REM, and total sleep time in telemetrized rats and decreased the latency to the first episode of persistent non-REM and REM sleep compared with vehicle-treated animals. The pharmacological profiles in the rat were similar to each other and comparable to other DORAs described in literature (Aissaoui et al., 2008; Boss et al., 2008, 2014; Cox et al., 2010; Sifferlen et al., 2010, 2013, 2015; Winrow et al., 2012; Heidmann et al., 2016). No clear differentiation between compounds was therefore possible on the basis of drug efficacy in rats.

In contrast, the benzimidazoles exhibited significant interspecies differences in key parameters driving drug distribution and clearance (Table 7). Metabolic stability in liver microsomes differed by 7.2- to 14-fold between rat and human, whereas plasma protein binding, the major determinant for general tissue and specifically brain penetration, differed by 9 to 30 -fold. Ratios of unbound brain and plasma concentrations in the rat were below unity and increased with dose (Table 3). Nonlinear plasma protein binding was demonstrated for ACT541468 at concentrations relevant for rat pharmacology assessments but not clinical testing (Supplemental Table S3), which might, at least in part, contribute to the dose-dependent brain/plasma ratios. Other factors, such as P-gp or breast cancer resistance protein-mediated efflux might also play a role in rats but have been excluded for man. Pharmacokinetic behavior was therefore expected to significantly differ between rat and man, calling for a tailored approach for the

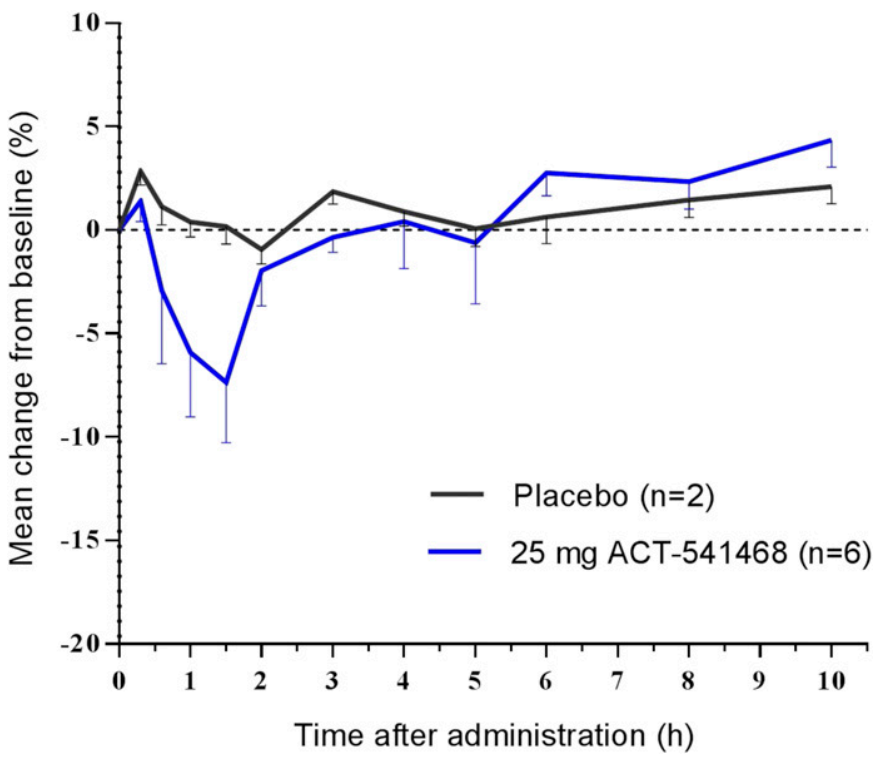

Fig. 10. Adaptive tracking performance of healthy male subjects after a $25 \mathrm{mg}$ dose of ACT-541468. Effect of $25 \mathrm{mg}$ ACT-541468 in an adaptive tracking test in healthy male subjects $(n=6)$ over a period of 10 hours postdosing, expressed as mean change \pm S.D. from baseline, and compared with placebo $(n=2)$. 
identification of a candidate drug exhibiting, beyond rapid sleep onset and efficacy, a sleep maintenance in man not longer than 8 hours.

The pharmacokinetic differences predicted for these benzimidazoles are mostly a reflection of differences in drug CL and tissue distribution (Table 6 and Fig. 7A). ACT-541468 had a 6-12 times higher simulated CL compared with ACT-605143 and ACT-658090 (Table 6), resulting from its $\mathrm{CL}_{\text {int }}$ in liver microsomes and the lowest binding to plasma and liver microsomal proteins (Table 7). On the other hand, ACT-541468 exhibited a larger simulated volume of distribution, i.e., $0.5 \mathrm{l} / \mathrm{kg}$ versus $0.2 \mathrm{l} / \mathrm{kg}$, in line with its lower plasma protein binding and distribution coefficient $(\log \mathrm{D})$. The combination of higher clearance and larger volume of distribution resulted in a simulated initial ACT-541468 plasma half-life of only 4.3 hours, which favorably compared with the 10.4 hours and 26.8 hours of ACT605143 or ACT-658090, respectively, and also to suvorexant with a simulated half-life of 8.7 hours. It is noteworthy, that these differences in pharmacokinetic profiles were not obvious from simple inspection of the individual modeling input data such as $\mathrm{CL}_{\text {int }}$, plasma, or microsomal binding, $\mathrm{pK}_{\mathrm{a}}$ and $\log \mathrm{D}$, which were all within a 2- to threefold range.

Published data on human pharmacodynamics and pharmacokinetics of 200-mg almorexant (Hoever et al., 2012a) and 50-mg suvorexant (Sun et al., 2013) after night-time administration were used as a basis to estimate active doses of the benzimidazoles in man. Initial inspection of the plasma concentration versus time profiles of both compounds at the end of the presumed 8-hour sleep period indicated residual almorexant and suvorexant plasma concentrations of $20 \mathrm{ng} / \mathrm{ml}$ and $240 \mathrm{ng} / \mathrm{ml}$, respectively (Fig. 8). This 12 -fold difference in total plasma concentrations between both compounds appeared somewhat surprising in light of apparently identical $\mathrm{OX}_{2}$ receptor potency in cellular assays (Table 1). Introducing corrections for molecular weight, plasma protein binding, and non-specific binding in the orexin binding assays (Table 7) yielded comparable unbound almorexant and suvorexant concentrations of 1.5 and 2.3 , when expressed as multiples of their respective unbound $K_{b}$ values at $\mathrm{OX}_{2}$. PBPK-PD models constructed for both antagonists yielded consistent levels of $\mathrm{OX}_{2}$ receptor occupancy of $63-66 \%$ at the end of an 8-hour period (Table 8). A very similar threshold of 65-80\% was recently reported for other DORAs in rat and dog (Gotter et al., 2013). Although almorexant and suvorexant both exhibited the same degree of $\mathrm{OX}_{2}$ receptor blockade at 8 hours postdose, only suvorexant was associated with impaired next-day performance (Citrome, 2014; Vermeeren et al., 2015). In addition to the absolute values in $\mathrm{OX}_{2}$ blockade, their rate of decline at the end of the sleep period was identified as a second key factor determining the absence of next day effects. The $65 \% \mathrm{OX}_{2}$ threshold was then used as guidance for predicting active doses of the benzimidazoles (Fig. 7B). The time course of $\mathrm{OX}_{2}$ receptor blockade generally followed plasma concentrations for all three compounds. Major differences were, however, observed in the magnitude of $\mathrm{OX}_{2}$ blockade. Despite the lowest simulated total plasma exposure, ACT541468 elicited the highest peak $\mathrm{OX}_{2}$ receptor blockade of $79 \%$, whereas only $59 \%$ was reached with ACT-605143. Differences in plasma protein binding compensated for the 2.9-fold higher total plasma concentrations of ACT-605143, resulting in almost equal unbound peak concentrations of ACT-541468 in brain, i.e., $1.1 \mathrm{nM}$ versus $0.96 \mathrm{nM}$. At 8 hours postdose, $\mathrm{OX}_{2}$ receptor occupancies were 58\% for ACT-541468 and 53\% for
ACT-605143, indicating that both compounds met the requirement to maintain sleep over an 8-hour period. Slightly lower $\mathrm{OX}_{2}$ receptor occupancies than those deduced from clinical data on almorexant and suvorexant were targeted on purpose to compensate for the higher drug concentrations expected after night-time dosing (Hoever et al., 2012a; Sun et al., 2013), which PBPK-PD modeling was technically unable to capture. Compared with ACT-605143, the decline in $\mathrm{OX}_{2}$ receptor occupancy was faster with ACT-541468, in line with the higher CL, lower $\mathrm{V}_{\mathrm{ss}}$, and resulting shorter half-life (Table 6). On the basis of PBPK-PD modeling, ACT-658090 was predicted to elicit a maximum $\mathrm{OX}_{2}$ receptor blockade of only $15 \%$. This somewhat surprising outcome in light of the excellent pharmacokinetic profile (Fig. 7A) is best explained by the lower $\mathrm{OX}_{2}$ receptor potency combined with very high plasma binding (Table 7), resulting in insufficient unbound drug levels in brain to elicit relevant $\mathrm{OX}_{2}$ receptor blockade. On the basis of above analysis and its overall favorable profile in terms of animal pharmacology, early safety and drug-drug interaction potential (A.T., unpublished observation), ACT-541468 was selected for clinical development.

The pharmacokinetic profile of ACT-541468 in healthy subjects was characterized after daytime and night-time administration in two Phase 1 studies, whereas its pharmacodynamics were assessed during the first 10 hours after daytime administration using a battery of objective and subjective assessments. Observed PK parameters at a dose of $25 \mathrm{mg}$ (Table 8 and Fig. 9) indicated rapid oral absorption after daytime administration, with peak plasma concentrations of $1400 \mathrm{nM}$ being reached within 1 hour. Plasma $\mathrm{AUC}_{0-24 \mathrm{~h}}$ was well predicted within a $14 \%$ range. The observed initial half-life was 3.0 hours and thus slightly shorter than the simulated value of 4.3 hours, well in accordance with the higher observed CL, i.e., $1.0 \mathrm{ml} / \mathrm{min}$ per kilogram versus predicted $1.2 \mathrm{ml} / \mathrm{min}$ per kilogram, and lower $\mathrm{V}_{\mathrm{ss}}, 0.4 \mathrm{l} / \mathrm{kg}$ versus $0.5 \mathrm{l} / \mathrm{kg}$ (Table 6 ). The terminal half-life of ACT-541468 was about 6 hours (Muehlan et al., 2017). After night-time dosing of ACT-541468, mean peak plasma concentrations only reached $1050 \mathrm{nM}$, whereas $\mathrm{AUC}_{0-24 \mathrm{~h}}$ increased by $27 \%$ to $8270 \mathrm{nM} \cdot \mathrm{h}$. Oral absorption was slightly delayed, with a $\mathrm{T}_{\max }$ of 1.5 hours, and plasma half-life increased from 3.0 to 5.1 hours. The differences between ACT-541468 daytime and night-time pharmacokinetics may result from differences in physiology between night and day such as intestinal motility and perfusion, or liver blood flow. It is important to note, that the observed differences in ACT-541468 PK were rather small, in contrast to the significantly delayed oral absorption and reduced plasma levels after night-time administration of almorexant (Table 8 and Fig. 8) (Hoever et al., 2012a). From a methodological point of view, it is noteworthy that PK simulations were run with a total of 100 subjects, whereas the observed PK data are means of only six and four healthy subjects, which might not properly represent a larger population. Pharmacodynamically, $25 \mathrm{mg}$ ACT-541468 revealed significantly reduced vigilance and attention (Fig. 10) and had clear effects on visuomotor coordination and postural stability. Onset of effects was observed within 1 hour, and returned to baseline within 3-6 hours. These early assessments in healthy subjects after daytime dosing suggest that a 25-mg dose has the potential to elicit the desired sleep effects in insomnia patients.

In conclusion, we have described the discovery of the dual orexin receptor antagonist ACT-541468 on the basis of early use of PBPK and PD modeling as part of the lead optimization 
process. ACT-541468 was identified out of a larger set of structurally related derivatives on the basis of its simulated $\mathrm{OX}_{2}$ receptor occupancy, targeting for an effect duration of about 8 hours at a $25 \mathrm{mg}$ dose, and a sufficiently short half-life to minimize next-day effects. Phase I clinical trials with ACT541468 in healthy subjects confirmed PBPK model-based predictions, as ACT-541468 reached peak plasma concentrations within 1 hour after dosing and exhibited an initial plasma half-life of only 3 hours. Drug exposure at a dose of $25 \mathrm{mg}$ reduced vigilance and attention, and impaired visuomotor coordination and postural stability in healthy subjects after daytime administration. Differences between night-time and daytime PK performance may result from changes in physiology between day and night but are not expected to negatively impact on performance of ACT-541468 in insomnia patients.

\section{Acknowledgments}

The authors thank Stephane Delahaye, Susanne Globig, Bruno Capeleto, Charlyse Herrmann, Pascal Rebmann, Daniela Kruesi, Marc Candreia, Ursula Fusco-Hug, Thomas Sasse, Katalin Menyhart, Celia Müller, Cédric Fischer, Hélène Massinet, and Hélène Roellinger for their dedication and expert experimental contributions. The authors thank Alexey Veligodskiy for help in the writing of the manuscript.

\section{Authorship Contributions}

Participated in research design: Treiber, de Kanter, Roch, Gatfield, Boss, von Raumer, Muehlan.

Conducted experiments: Treiber, de Kanter, Roch, Gatfield, Boss, von Raumer, Muehlan, van Gerven.

Performed data analysis: Treiber, de Kanter, Roch, Gatfield, Boss, von Raumer, Muehlan.

Wrote or contributed to the writing of the manuscript: Treiber, de Kanter, Roch, Gatfield, Boss, Schindelholz, Jenck.

\section{References}

Aissaoui H, Koberstein R, Zumbrunn C, Gatfield J, Brisbare-Roch C, Jenck F, Treiber $\mathrm{A}$, and Boss C (2008) N-Glycine-sulfonamides as potent dual orexin 1/orexin 2 receptor antagonists. Bioorg Med Chem Lett 18:5729-5733.

Baxter CA, Cleator E, Brands KMJ, Edwards JS, Reamer RA, Sheen FJ, Stewart GW, Strotman NA, and Wallace DJ (2011) The first large-scale synthesis of MK-4305: a dual orexin receptor antagonist for the treatment of sleep disorder. Org Process Res Dev 15:367-375.

Bettica P, Nucci G, Pyke C, Squassante L, Zamuner S, Ratti E, Gomeni R, and Alexander R (2012a) Phase I studies on the safety, tolerability, pharmacokinetics and pharmacodynamics of SB-649868, a novel dual orexin receptor antagonist. J Psychopharmacol 26:1058-1070.

Bettica P, Squassante L, Groeger JA, Gennery B, Winsky-Sommerer R, and Dijk DJ (2012b) Differential effects of a dual orexin receptor antagonist (SB-649868) and zolpidem on sleep initiation and consolidation, SWS, REM sleep, and EEG power spectra in a model of situational insomnia. Neuropsychopharmacology $\mathbf{3 7}$ 1224-1233

Bonaventure P, Shelton J, Yun S, Nepomuceno D, Sutton S, Aluisio L, Fraser I, Lord B, Shoblock J, Welty N, et al. (2015a) Characterization of JNJ-42847922, a selective orexin-2 receptor antagonist, as a clinical candidate for the treatment of insomnia. J Pharmacol Exp Ther 354:471-482.

Bonaventure P, Yun S, Johnson PL, Shekhar A, Fitz SD, Shireman BT, Lebold TP, Nepomuceno D, Lord B, Wennerholm M, et al (2015b) A selective orexin-1 receptor antagonist attenuates stress-induced hyperarousal without hypnotic effects. $J$ Pharmacol Exp Ther 352:590-601.

Boss C, Brotschi C, Gude M, Heidmann B, Sifferlen T, Von Raumer M, and Williams JT (2015a) inventors, Idorsia Pharmaceuticals Ltd, assignee. Crystalline form of (s)-(2-(6-chloro-7-methyl-1h-benzo[d]imidazol-2-yl)-2-methylpyrrolidin-1-yl)(5-methoxy2-(2H-1,2,3-triazol-2-yl)phenyl)methanone and its use as orexin receptor antagonists. Publ. no. WO/2015/083070. International application number: PCT/IB2014/066508 2015 Nov 6.

Boss C, Brotschi C, Gude M, Heidmann B, Sifferlen T, and Williams JT (2013) inventors, Idorsia Pharmaceuticals Ltd, assignee. Benzimidazole-proline derivatives. Publ. no. WO/2013/182972. International application number: PCT/IB2013/054567. 2013 Dec 12.

Boss C, Roch C, Brotschi C, Gude M, Heidmann B, Jenck F, Sifferlen T, Steiner MA and Williams JT (2015b) inventors, Idorsia Pharmaceuticals Ltd, assignee. Use of benzimidazole-proline derivatives. Publ. no. WO/2015/083094. International appl. no. PCT/IB2014/066548. 2015 Nov 6.

Boss C, Roch C, Jenck F, Aissaoui H, Koberstein R, Sifferlen T, and Weller T (2008) Orexin receptor antagonism: a new principle in neuroscience. Chimia (Aarau) 62:974-979.

Boss C, Roch-Brisbare C, Steiner MA, Treiber A, Dietrich H, Jenck F, von Raumer M, Sifferlen T, Brotschi C, Heidmann B, et al. (2014) Structure-activity relationship, biological, and pharmacological characterization of the proline sulfonamide ACT462206: a potent, brain-penetrant dual orexin 1/orexin 2 receptor antagonist. ChemMedChem 9:2486-2496.

Carter ME, Schaich Borg J, and de Lecea L (2009) The brain hypocretins and their receptors: mediators of allostatic arousal. Curr Opin Pharmacol 9:39-45.

Cheng Y and Prusoff WH (1973) Relationship between the inhibition constant (K1) and the concentration of inhibitor which causes 50 per cent inhibition (I50) of an enzymatic reaction. Biochem Pharmacol 22:3099-3108.

Citrome L (2014) Suvorexant for insomnia: a systematic review of the efficacy and safety profile for this newly approved hypnotic - what is the number needed to treat, number needed to harm and likelihood to be helped or harmed? Int J Clin Pract 68:1429-1441.

Connor KM, Mahoney E, Jackson S, Hutzelmann J, Zhao X, Jia N, Snyder E, Snavely D, Michelson D, Roth T, et al. (2016) A phase II dose-ranging study evaluating the efficacy and safety of the orexin receptor antagonist filorexant (MK-6096) in patients with primary insomnia. Int $J$ Neuropsychopharmacol 19:pyw022 DOI: 10.1093/ijnp/pyw022.

Cox CD, Breslin MJ, Whitman DB, Schreier JD, McGaughey GB, Bogusky MJ, Roecker AJ, Mercer SP, Bednar RA, Lemaire W, et al. (2010) Discovery of the dual orexin receptor antagonist [(7R)-4-(5-chloro-1,3-benzoxazol-2-yl)-7-methyl-1,4diazepan-1-yl] [5-methyl-2-(2H-1,2,3-triazol-2-yl)phenyl]methanone (MK-4305) for the treatment of insomnia. J Med Chem 53:5320-5332.

Cui D, Cabalu T, Yee KL, Small J, Li X, Liu B, Maciolek C, Smith S, Liu W, McCrea $\mathrm{JB}$, et al. (2016) In vitro and in vivo characterisation of the metabolism and disposition of suvorexant in humans. Xenobiotica 46:882-895.

de Kanter R, Sidharta PN, Delahaye S, Gnerre C, Segrestaa J, Buchmann S, Kohl C, and Treiber A (2016) Physiologically-based pharmacokinetic modeling of macitentan: prediction of drug-drug interactions. Clin Pharmacokinet 55:369-380.

de Lecea L, Kilduff TS, Peyron C, Gao X, Foye PE, Danielson PE, Fukuhara C, Battenberg EL, Gautvik VT, Bartlett, 2ndFS, et al. (1998) The hypocretins: hypothalamus-specific peptides with neuroexcitatory activity. Proc Natl Acad Sci USA 95:322-327.

Dingemanse J, Cruz HG, Gehin M, and Hoever P (2014) Pharmacokinetic interactions between the orexin receptor antagonist almorexant and the CYP3A4 inhibitors ketoconazole and diltiazem. $J$ Pharm Sci 103:1548-1556.

Dugovic C, Shelton JE, Yun S, Bonaventure P, Shireman BT, and Lovenberg TW (2014) Orexin-1 receptor blockade dysregulates REM sleep in the presence of orexin-2 receptor antagonism. Front Neurosci 8:28 DOI: 10.3389/fnins.2014.00028

Frey DJ, Ortega JD, Wiseman C, Farley CT, and Wright, JrKP (2011) Influence of zolpidem and sleep inertia on balance and cognition during nighttime awakening: a randomized placebo-controlled trial. J Am Geriatr Soc 59:73-81.

Glass J, Lanctôt KL, Herrmann N, Sproule BA, and Busto UE (2005) Sedative hypnotics in older people with insomnia: meta-analysis of risks and benefits. BMJ 331:1169 10.1136/bmj.38623.768588.47.

Gotter AL, Forman MS, Harrell CM, Stevens J, Svetnik V, Yee KL, Li X, Roecker AJ, Fox SV, Tannenbaum PL, et al. (2016) Orexin 2 receptor antagonism is sufficient to promote NREM and REM sleep from mouse to man. Sci Rep 6:27147 10.1038/ srep27147.

Gotter AL, Winrow CJ, Brunner J, Garson SL, Fox SV, Binns J, Harrell CM, Cui D, Yee KL, Stiteler M, et al. (2013) The duration of sleep promoting efficacy by dual orexin receptor antagonists is dependent upon receptor occupancy threshold. BMC Neurosci 14:90 10.1186/1471-2202-14-90.

Gozzi A, Turrini G, Piccoli L, Massagrande M, Amantini D, Antolini M, Martinelli P, Cesari N, Montanari D, Tessari M, et al. (2011) Functional magnetic resonance imaging reveals different neural substrates for the effects of orexin-1 and orexin-2 receptor antagonists. PLoS One 6: 16406

Heidmann B, Gatfield J, Roch C, Treiber A, Tortoioli S, Brotschi C, Williams JT, Bolli MH, Abele S, Sifferlen T, et al. (2016) Discovery of highly potent dual orexin receptor antagonists via a scaffold-hopping approach. ChemMedChem 11:2132-2146 $10.1002 / \mathrm{cmdc} .201600175$

Herring WJ, Snyder E, Budd K, Hutzelmann J, Snavely D, Liu K, Lines C, Roth T, and Michelson D (2012) Orexin receptor antagonism for treatment of insomnia: randomized clinical trial of suvorexant. Neurology 79:2265-2274.

Hoch M, Hoever P, Zisowsky J, Priestley A, Fleet D, and Dingemanse J (2012) Absolute oral bioavailability of almorexant, a dual orexin receptor antagonist, in healthy human subjects. Pharmacology 89:53-57.

Hoever P, de Haas SL, Dorffner G, Chiossi E, van Gerven JM, and Dingemanse J (2012a) Orexin receptor antagonism: an ascending multiple-dose study with almorexant. J Psychopharmacol 26:1071-1080.

Hoever P, Dorffner G, Beneš H, Penzel T, Danker-Hopfe H, Barbanoj MJ, Pillar G, Saletu B, Polo O, Kunz D, et al. (2012b) Orexin receptor antagonism, a new sleepenabling paradigm: a proof-of-concept clinical trial. Clin Pharmacol Ther 91:975-985. Jacobson LH, Chen S, Mir S, and Hoyer D (2017) Orexin OX2 receptor antagonists as sleep aids. Curr Top Behav Neurosci 33:105-136.

Jamei M, Turner D, Yang J, Neuhoff S, Polak S, Rostami-Hodjegan A, and Tucker G (2009) Population-based mechanistic prediction of oral drug absorption. AAPS J 11:225-237.

Johnson PL, Samuels BC, Fitz SD, Lightman SL, Lowry CA, and Shekhar A (2012) Activation of the orexin 1 receptor is a critical component of $\mathrm{CO}_{2}$-mediated anxiety and hypertension but not bradycardia. Neuropsychopharmacology 37:1911-1922.

Jones HM, Gardner IB, and Watson KJ (2009) Modelling and PBPK simulation in drug discovery. AAPS $J$ 11:155-166.

Mahler SV, Moorman DE, Smith RJ, James MH, and Aston-Jones G (2014) Motivational activation: a unifying hypothesis of orexin/hypocretin function. Nat Neurosci 17:1298-1303.

Mangion IK, Sherry BD, Yin J, and Fleitz FJ (2012) Enantioselective synthesis of a dual orexin receptor antagonist. Org Lett 14:3458-3461.

Merlo Pich E and Melotto S (2014) Orexin 1 receptor antagonists in compulsive behavior and anxiety: possible therapeutic use. Front Neurosci 8:26 DOI: 10.3389/ fnins.2014.00026 
Mieda M, Hasegawa E, Kisanuki YY, Sinton CM, Yanagisawa M, and Sakurai T (2011) Differential roles of orexin receptor-1 and -2 in the regulation of non-REM and REM sleep. $J$ Neurosci 31:6518-6526.

Miller TR, Witte DG, Ireland LM, Kang CH, Roch JM, Masters JN, Esbenshade TA, and Hancock AA (1999) Analysis of apparent noncompetitive responses to competitive $\mathrm{H}(1)$-histamine receptor antagonists in fluorescent imaging plate readerbased calcium assays. J Biomol Screen 4:249-258.

Muehlan C, Juif PE, Van Gerven J, Heuberger J, and Dingemanse J (2017) First-inman study of ACT-541468, a novel dual orexin receptor antagonist: characterization of its pharmacokinetics, pharmacodynamics, safety and tolerability. In: American Society for Clinical Pharmacology and Therapeutics 2017 Annual Meeting Abstracts. Clin Pharmacol Ther 101:S5-S99.

Otmani S, Demazières A, Staner C, Jacob N, Nir T, Zisapel N, and Staner L (2008) Effects of prolonged-release melatonin, zolpidem, and their combination on psychomotor functions, memory recall, and driving skills in healthy middle aged and elderly volunteers. Hum Psychopharmacol 23:693-705.

Peyron C, Faraco J, Rogers W, Ripley B, Overeem S, Charnay Y, Nevsimalova S, Aldrich M, Reynolds D, Albin R, et al. (2000) A mutation in a case of early onset narcolepsy and a generalized absence of hypocretin peptides in human narcoleptic brains. Nat Med 6:991-997.

Ramirez AD, Gotter AL, Fox SV, Tannenbaum PL, Yao L, Tye SJ, McDonald T, Brunner J, Garson SL, Reiss DR, et al. (2013) Dual orexin receptor antagonists show distinct effects on locomotor performance, ethanol interaction and sleep architecture relative to gamma-aminobutyric acid-A receptor modulators. Front Neurosci 7:254 DOI: 10.3389/fnins 2013.00254.

Rodgers T and Rowland M (2007) Mechanistic approaches to volume of distribution predictions: understanding the processes. Pharm Res 24:918-933.

Sakurai T (1999) Orexins and orexin receptors: implication in feeding behavior. Regul Pept 85:25-30.

Sakurai T (2007) The neural circuit of orexin (hypocretin): maintaining sleep and wakefulness. Nat Rev Neurosci 8:171-181.

Sifferlen T, Boller A, Chardonneau A, Cottreel E, Gatfield J, Treiber A, Roch C, Jenck F, Aissaoui H, Williams JT, et al. (2015) Substituted pyrrolidin-2-ones: Centrally acting orexin receptor antagonists promoting sleep. Part 2. Bioorg Med Chem Let 25:1884-1891.

Sifferlen T, Boss C, Cottreel E, Koberstein R, Gude M, Aissaoui H, Weller T, Gatfield J, Brisbare-Roch C, and Jenck F (2010) Novel pyrazolo-tetrahydropyridines as potent orexin receptor antagonists. Bioorg Med Chem Lett 20:1539-1542.

Sifferlen T, Koberstein R, Cottreel E, Boller A, Weller T, Gatfield J, Brisbare-Roch C Jenck F, and Boss C (2013) Synthesis, structure-activity relationship studies, and identification of novel 5,6,7,8-tetrahydroimidazo[1,5-a]pyrazine derivatives as dual orexin receptor antagonists. Part 1. Bioorg Med Chem Lett 23:2212-2216.

Sun H, Kennedy WP, Wilbraham D, Lewis N, Calder N, Li X, Ma J, Yee KL, Ermlich S, Mangin E, et al. (2013) Effects of suvorexant, an orexin receptor antagonist, on sleep parameters as measured by polysomnography in healthy men. Sleep 36:259-267.

Sun H, Yee KL, Gill S, Liu W, Li X, Panebianco D, Mangin E, Morrison D, McCrea J, Wagner JA, et al. (2015) Psychomotor effects, pharmacokinetics and safety of the orexin receptor antagonist suvorexant administered in combination with alcohol in healthy subjects. J Psychopharmacol 29:1159-1169.

Tannenbaum PL, Tye SJ, Stevens J, Gotter AL, Fox SV, Savitz AT, Coleman PJ, Uslaner JM, Kuduk SD, Hargreaves R, et al. (2016) Inhibition of orexin signaling promotes sleep yet preserves salient arousability in monkeys. Sleep $\mathbf{3 9}$ : 603-612.

TGA (2014) Extract from the clinical evaluation report for suvorexant. Available at: www.tga.gov.au/sites/default/files/auspar-suvorexant-150411-cer.pdf. Accessed on: November 11, 2016. Australian Government, Department of Health, Therapeutic Goods Administration.

Thannickal TC, Moore RY, Nienhuis R, Ramanathan L, Gulyani S, Aldrich M, Cornford M, and Siegel JM (2000) Reduced number of hypocretin neurons in human narcolepsy. Neuron 27:469-474.

Tsujino N and Sakurai T (2009) Orexin/hypocretin: a neuropeptide at the interface of sleep, energy homeostasis, and reward system. Pharmacol Rev 61:162-176.

Vermeeren A, Sun H, Vuurman EF, Jongen S, Van Leeuwen CJ, Van Oers AC, Palcza $\mathrm{J}, \mathrm{Li}$ X, Laethem T, Heirman I, et al. (2015) On-the-road driving performance the morning after bedtime use of suvorexant 20 and $40 \mathrm{mg}$ : a study in non-elderly healthy volunteers. Sleep 38:1803-1813.

Verzijl GKM, de Vries AHM, de Vries JG, Kapitan P, Dax T, Helms M, Nazir Z, Skranc W, Imboden C, Stichler J, et al. (2013) Catalytic asymmetric reduction of a 3,4-dihydroisoquinoline for the large-scale production of almorexant: hydrogenation or transfer hydrogenation? Org Process Res Dev 17:1531-1539.

Winrow CJ, Gotter AL, Cox CD Tannenbaum PL, Garson SL, Doran SM, Breslin MJ, Schreier JD, Fox SV, Harrell CM, et al. (2012) Pharmacological characterization of MK-6096 - a dual orexin receptor antagonist for insomnia. Neuropharmacology 62 : 978-987.

Yoshida Y, Naoe Y, Terauchi T, Ozaki F, Doko T, Takemura A, Tanaka T, Sorimach $K$, Beuckmann CT, Suzuki M, et al. (2015) Discovery of $(1 \mathrm{R}, 2 \mathrm{~S})-2-[(2,4$ Dimethylpyrimidin-5-yl)oxy]methyl-2-(3-fluorophenyl)-N-(5-fluoropyridin-2yl)cyclopropanecarboxamide (E2006): A Potent and Efficacious Oral Orexin Receptor Antagonist. J Med Chem 58:4648-4664.

Zammit GK (2007) The prevalence, morbidities, and treatments of insomnia. CNS Neurol Disord Drug Targets 6:3-16.

Address correspondence to: Dr. Alexander Treiber, Idorsia Pharmaceuticals Ltd, Hegenheimermattweg 91, 4123 Allschwil, Switzerland. E-mail: alexander.treiber@idorsia.com 